\title{
Revealed incomplete preferences under uncertainty
}

Citation for published version (APA):

Cettolin, E., \& Riedl, A. M. (2015). Revealed incomplete preferences under uncertainty. Maastricht University, Graduate School of Business and Economics. GSBE Research Memoranda No. 016 https://doi.org/10.26481/umagsb.2015016

Document status and date:

Published: 01/01/2015

DOI:

10.26481/umagsb.2015016

Document Version:

Publisher's PDF, also known as Version of record

\section{Please check the document version of this publication:}

- A submitted manuscript is the version of the article upon submission and before peer-review. There can be important differences between the submitted version and the official published version of record.

People interested in the research are advised to contact the author for the final version of the publication, or visit the DOI to the publisher's website.

- The final author version and the galley proof are versions of the publication after peer review.

- The final published version features the final layout of the paper including the volume, issue and page numbers.

Link to publication

\footnotetext{
General rights rights.

- You may freely distribute the URL identifying the publication in the public portal. please follow below link for the End User Agreement:

www.umlib.nl/taverne-license

Take down policy

If you believe that this document breaches copyright please contact us at:

repository@maastrichtuniversity.nl

providing details and we will investigate your claim.
}

Copyright and moral rights for the publications made accessible in the public portal are retained by the authors and/or other copyright owners and it is a condition of accessing publications that users recognise and abide by the legal requirements associated with these

- Users may download and print one copy of any publication from the public portal for the purpose of private study or research.

- You may not further distribute the material or use it for any profit-making activity or commercial gain

If the publication is distributed under the terms of Article $25 \mathrm{fa}$ of the Dutch Copyright Act, indicated by the "Taverne" license above, 


\section{Maastricht University}

Elena Cettolin, Arno Riedl

Revealed Incomplete

Preferences under

Uncertainty

RM/15/016

\section{GSBE}

Maastricht University School of Business and Economics

Graduate School of Business and Economics

P.O Box 616

NL-6200 MD Maastricht

The Netherlands 


\title{
Revealed Incomplete Preferences under Uncertainty*
}

\author{
Elena Cettolin \\ Arno Riedl \\ Tilburg University \\ Maastricht University
}

May 11, 2015

\begin{abstract}
The completeness axiom of choice has been questioned for long, and in response, theoretical models of decision making allowing for incomplete preferences have been developed. So far the theoretical accomplishments have however not been paired with empirical evidence on the actual existence of incomplete preferences. In this paper we provide empirical evidence in support of the existence of incomplete preferences due to multiple priors over an ambiguous event. We design experimental decision tasks where specific choice patterns are consistent with incomplete preferences under uncertainty but inconsistent with models assuming complete preferences. We find that approximately half of the subjects behave consistent with incomplete preferences due to multiple priors and that the observed behavioral pattern cannot be attributed to mistakes, probability weighting or regret aversion. In a robustness test we show that the observed behavior is robust to a prize variation in the ambiguous prospect and consistent with comparative statics predictions based on incomplete preferences under uncertainty.
\end{abstract}

Keywords: Incomplete preferences, uncertainty, multiple priors, experiment JEL Classification: C91, D01, D81

\footnotetext{
*Elena Cettolin: Department of Economics, Tilburg School of Economics and Management, Tilburg University, P.O.Box 90153, 5000 LE Tilburg, the Netherlands, e.cettolin@uvt.nl; Arno Riedl (corresponding author): CESifo, IZA, Netspar, Department of Economics (AE1), School of Economics and Business, Maastricht University, P.O.Box 616, 6200 MD Maastricht, the Netherlands, a.riedl@maastrichtuniversity.nl. Earlier versions of this paper have been presented at Berlin Behavioral Economics Seminar, Columbia Business School, CREED University of Amsterdam, ESE Conference Rotterdam, IMEBE Granada, Paris School of Economics Roy Seminar, Rady School of Management UC San Diego, SITE Psychology and Economics Stanford University, Stockholm School of Economics, and University of Vienna. We are grateful to the participants for many very valuable comments. The research documented in this paper was partly financed by the Oesterreichische Nationalbank (project number 11429) and also received financial support from the Netherlands Organisation for Scientific Research (NWO) (project number 400-09-451).
} 


\section{Introduction}

It is a standard assumption in economics that individuals are able to pair-wise compare all available choice options. In other words, it is assumed that decision makers have complete preferences. Although core to most decision making models, the completeness assumption has been questioned since a long time. Both, on the grounds that it may be intuitively too demanding and not even appealing normatively. In the words of Aumann (1962): "Like others of the axioms, [completeness] is inaccurate as a description of real life; but unlike them, we find it hard to accept even from the normative viewpoint" (p.446). More recently, Wakker (2010) thoroughly discusses problems of the completeness assumption in models for decision making under risk and uncertainty. In this paper we provide empirical evidence in support of the existence of incomplete preferences under uncertainty.

Many crucial 'real life' choices are between risky and ambiguous prospects and knowledge about (in)completeness of preferences under uncertainty is thus important also from an applied viewpoint. For instance, in medical decision making frequently choices have to be made between traditional treatments with known success rates and side effects and novel treatments with unknown success rates and side effects. A prominent recent example at hand is the (discussion regarding the) application of experimental vaccines during the 2014-2015 Ebola outbreak in West Africa (Alang, 2015) 1 Another, less dramatic example is the choice between a secure investment possibility with a known but perhaps low success rate and a highly uncertain investment with an unknown but potentially high success probability. Similarly, financial markets arguably exhibit high uncertainty and investors may have to choose between investing in risky bonds and ambiguous assets (e.g., Mukerii and Tallon, 2001). In such cases models of incomplete preferences are likely delivering different predictions and prescriptions than models of complete preferences (e.g., Bossaerts et al., 2010) and it is, thus, important to know if economic agents indeed exhibit incomplete preferences. Moreover, not all people may exhibit incomplete preferences or the extent of incompleteness may differ across them. If so, it could be important for policy ends to have a tool that discriminates between different types of (in)completeness.

Starting with the cited work of Aumann, the above described intuitive doubts and practical importance led to the development of a number of theoretical models that drop the completeness axiom and allow the decision maker to remain occasionally indecisive. In these models a decision maker (henceforth, DM) may be indecisive when pursuing different, and possibly orthogonal, objectives which lead to multiple representations of the same choice option (see, e.g., Ok, 2002; Dubra et al., 2004; Ok et al., 2012, on multi-objective decision making). Further, a DM may

\footnotetext{
${ }^{1}$ For more information see, e.g., http://www . who.int/mediacentre/factsheets/fs103/en/
} 
be indecisive when lacking the information necessary to determine which option is best, such as when choice objects are uncertain prospects (see, e.g., Bewley, 2002; Gilboa et al., 2010; Ok et al., 2012). More recently, theoretical models of incomplete preferences have also been employed to explain the emergence of choice anomalies, such as the status quo bias and preference reversals (see, among others, Mandler, 2004, 2005; Masatlioglu and Ok, 2005; Eliaz and Ok, 2006; Ortoleva, 2010).

So far the theoretical accomplishments have however not been paired with empirical evidence on the actual existence of incomplete preferences 2 The laboratory experiment of Danan and Ziegelmeyer (2006), reported in a working paper, constitutes the only empirical work in economics known to us that explicitly looks for incompleteness of preferences. In this experiment, it is observed that subjects postpone choices between risky prospects and sure amounts to a future session, even when postponing comes at a small cost. The authors claim that such decisions reveal "true indecisiveness." However, for this interpretation to hold it needs to be assumed that there is a link between incomplete preferences and the concept of preference for flexibility 3

Generally, a major obstacle to obtaining convincing empirical evidence on incomplete preferences resides in the fact that preferences need to be revealed via choice. For instance, indecisiveness due to incomplete preferences may be difficult to distinguish from preference indifference. Therefore, incomplete preferences may remain hidden unless some specific assumptions are introduced (as in the work cited above).

In this paper we employ an empirical strategy that circumvents this problem by using decision tasks where specific choice patterns are consistent with incomplete preferences under uncertainty but inconsistent with models assuming complete preferences. Specifically, we present the results of three experiments that together can reveal the existence of incomplete preference relations, due to multiple priors over an ambiguous event.

In the first experiment, denoted Risk-Ambi, subjects face a series of decision situations where they are presented a risky and an ambiguous prospect. All prospects, risky and ambiguous, are characterized by the same two possible outcomes, and level and source of ambiguity are kept constant in all decision situations. For the risky prospect the likelihood of winning a positive prize differs across decision situations, in the range of 0 percent to 100 percent. In each of these situations, a subject can either choose one of the two prospects, or select an indifference option (option $I$ ), which delegates the choice between the two prospects to a fair random device. Im-

\footnotetext{
${ }^{2}$ One may sense here a similarity to the search of the Higgs boson in physics where also theory predicted its existence long before its actual existence was empirically suggested (Aad et al., 2012).

${ }^{3}$ See Kraus and Sagi (2006) for a theoretical model.
} 
portantly, the choice task is designed in a way such that any model assuming a single prior on the ambiguous event, or assuming a decision rule that reduces to a single prior representation of the ambiguous prospect (Cerreia-Vioglio et al., 2011), predicts that subjects choose option $I$ at most once. If however subjects choose option $I$ multiple times, it is consistent with incomplete preferences due to holding multiple priors on the ambiguous prospect (Gilboa et al., 2010). Subjects are forced to make some choice and when holding multiple priors option $I$ is likely an attractive option as it allows avoiding an active choice between risky and ambiguous prospects. Moreover, the more dispersed the priors, the more decision situations in which prospects cannot be ranked and the more often option $I$ may be chosen.

To provide additional support for this interpretation, we also empirically test whether repeated choice of option $I$ could be consistent with other prominent theoretical models of decision making under uncertainty. First, we consider Prospect Theory, and more specifically the idea that people weight probabilities non-linearly (Tversky and Kahneman, 1992). To test this potential explanation, we implement a choice task that allows us to estimate subjects' probability weighting function at the individual level. Second, we consider the possibility of mistakes or 'thick indifference curves' and conduct an additional experiment, denoted Risk-Sure, where subjects make choices between risky prospects and a safe payment. If repeatedly choosing option $I$ were indeed due to mistakes unrelated to incomplete preferences, we should observe such a choice pattern also in this set-up. Finally, we conduct a third experiment, denoted Risk-Ambi-high, that is identical to Risk-Ambi, except that we increase the winning prize for the ambiguous prospect. We provide theoretical comparative statics predictions based on the assumption of incomplete preferences due to multiple priors and check if these predictions are carried out by the data.

In Risk-Ambi we find that as many as about half of the subjects choose option $I$ multiple times. These choices cannot be explained by likelihood insensitivity which, although present in our sample, is not pronounced enough to support this interpretation. This suggests already that the repeated choice of $I$ could be due to incomplete preferences over the ambiguous event. In Risk-Sure we observe, in stark contrast to the first experiment, that option $I$ is hardly ever chosen more than once. Hence, it is very unlikely that repeated choice of option $I$ is a result of mistakes or 'thick' indifference curves. Finally, in Risk-Ambi-high we observe again a large number of subjects choosing option $I$, proving that this behavioral pattern is robust to a change in incentives. Moreover, the comparative statics predictions based on incomplete preferences are largely confirmed. We are thus confident that the repeated choice of option $I$ is indeed an expression of incomplete preferences under uncertainty 4

\footnotetext{
${ }^{4}$ Our study and results are related to a few recent papers investigating a possible preference for randomness (Dominiak and Schnedler, 2011; Agranov and Ortoleva, 2013; Dwenger et al., 2014). We discuss these papers and how our work relates to them in Section 6
} 
The reminder of the paper is organized as follows. The next section lays out our general empirical strategy. Section 3 describes in detail the design and results of experiment Risk-Ambi, and Sections 4 and 5 report on experiments Risk-Sure and Risk-Ambi-high, respectively. The paper closes with a discussion and conclusions in Section 6 .

\section{Empirical Strategy}

Our empirical strategy to reveal incomplete preferences under uncertainty consists of running a series of decision making experiments. Each experiment has the same general structure and consists of three parts. In the first part, participants have to make a series of decisions where they have to choose between risky and ambiguous (or certain) prospects. Importantly, in each decision situation there is also the possibility to state indifference, effectively delegating the choice to a fair random device (henceforth, for brevity, option $I$ ). Our set-up is such that any model assuming a single prior on ambiguous events predicts at most one choice in favor of option $I$. In contrast, incomplete preferences under uncertainty, in the sense of multiple priors 5 can be revealed via repeated choices of option $I 6$ In the second part, participants face a lottery choice task that we use to elicit likelihood insensitivity. We use the data to estimate individual probability weighting functions and study their relation to choices in the first part. In the third part, subjects have to respond to questionnaires measuring some psychological constructs potentially important in decision making under uncertainty and individual background information.

In total we report on three experiments. Experiment Risk-Ambi sets the stage and provides our main result regarding repeated choices of option $I$ and suggests the existence of incomplete preferences. Experiment Risk-Sure tests whether our main result could be due to systematic mistakes or 'thick' indifference curves. In Experiment Risk-Ambi-high we explore robustness of our result in respect to increased prizes and test comparative statics predictions based on multiple priors models.

Next we describe Risk-Ambi, where we explain the different parts in more detail. Regarding choices in favor of option $I$, we provide theoretical predictions of different models of decision making under uncertainty.

\footnotetext{
${ }^{5}$ In the following, for convenience, we will abuse language a bit and talk about "incomplete preferences" when we mean "incomplete preferences under uncertainty, in the sense of multiple priors".

${ }^{6}$ We note that with our procedure we likely underestimate repeated choices of $I$ that are an expression of incomplete preferences. As participants are forced to make some choice in each decision situation, individuals with incomplete preferences may as well select the risky or ambiguous prospect. In this sense there may be unobserved incomplete preferences.
} 


\section{Experiment Risk-Ambi - Risk and Ambiguity}

The experiment consists of three parts. Subjects were not informed about the structure of the experiment and instructions for each part were administered on the computer screen only before the beginning of the respective part 7

\subsection{Part 1 - Decisions under Uncertainty}

In the first part of the experiment participants face a series of decision situations where they are asked to choose between a risky and an ambiguous prospect. Every decision situations is displayed in a row of a table on the computer screen, and all prospects are characterized by the same potential outcomes of $€ 15$ and $€ 0$. Risk is implemented by using a nontransparent urn filled with 100 balls, colored red or black. In the experiment we call it Urn A. The color composition of the urn varies in each decision situation by 5 balls. In the first decision situation the urn contains 100 red balls, in the second decision situation it contains 95 red balls and 5 black balls, and so on, until the 21st, and last, decision situation where the urn contains 100 black balls 8 The ambiguous prospect is the same in all decision situations. Ambiguity is also implemented with an urn, but now the urn contains 100 balls in unknown proportion of red and black. This urn is called Urn B in the experiment. To credibly implement ambiguity we applied the following procedure. The actual composition of Urn B is chosen by a fellow researcher at Maastricht University, who is completely free to choose the color composition, except that the total number of balls has to be 100. Our colleague then seals the urn and nobody except him, who is in no other way involved in the experiment, knows its composition. The urns are visibly placed in the experimental lab. Subjects are informed about the procedure and that they are free to inspect the contents of the urns after the experiment is over.

Table 1 reproduces some of the decision situations participants see on the computer screen 9 Before the decision situations are displayed, each subject has to choose her personal winning color, either red or black, which is the color associated with the high outcome of $€ 15$. Each of the 21 decision situations corresponds to a choice between the risky and the ambiguous prospect. Importantly, different to most experiments on decision making under uncertainty, in each decision situation, subjects can also avoid to actively select one of the prospects 10 Specifically,

\footnotetext{
${ }^{7}$ The instructions used in the experiment can be found in the Appendix.

${ }^{8} \mathrm{Urn} \mathrm{A}$ is publicly composed during the payment phase, after a random draw determines which one the 21 decision situations is relevant for payment.

${ }^{9}$ A screen shot of the actual decision table can be found in the Appendix D. To indicate their choice, participants had to click on a check box displayed to the left of each option.

10 Cohen et al. (1987) also allow for such an option.
} 
participants are informed that by choosing the middle option the choice between prospects is delegated to a fair chance device, which selects one of the two prospects with equal probability. For this option, we used the neutral phrase "I am indifferent between the two urns." to avoid any experimenter demand effect and connotation with respect to incompleteness. We refer to this option simply as option $I, 11$

Table 1: The decision situations

\begin{tabular}{cccc}
\hline $\begin{array}{c}\text { Decision } \\
\text { situation }\end{array}$ & $\begin{array}{c}\text { Composition } \\
\text { Urn A }\end{array}$ & & $\begin{array}{c}\text { Composition } \\
\text { Urn B }\end{array}$ \\
\hline 1. & 100 red balls & $\begin{array}{c}\text { I am indifferent } \\
\text { between the two urns. }\end{array}$ & $\begin{array}{c}100 \text { black and red balls } \\
\text { in unknown color ratio. }\end{array}$ \\
\hline 2. & $\begin{array}{c}95 \text { red balls }+ \\
5 \text { black balls }\end{array}$ & $\begin{array}{c}\text { I am indifferent } \\
\text { between the two urns. }\end{array}$ & $\begin{array}{c}100 \text { black and red balls } \\
\text { in unknown color ratio }\end{array}$ \\
\hline 3. & 90 red balls + & $\begin{array}{c}\text { I am indifferent } \\
\text { between the two urns. }\end{array}$ & $\begin{array}{c}100 \text { black and red balls } \\
\text { in unknown color ratio }\end{array}$ \\
\hline$\vdots$ & 10 black balls & $\vdots$ & $\vdots$ \\
\hline 10. & $\begin{array}{c}55 \text { red balls }+ \\
45 \text { black balls }\end{array}$ & $\begin{array}{c}\text { I am indifferent } \\
\text { between the two urns. }\end{array}$ & $\begin{array}{c}100 \text { black and red balls } \\
\text { in unknown color ratio }\end{array}$ \\
\hline$\vdots$ & $\vdots$ & $\vdots$ & $\vdots$ \\
\hline 20. & 5 red balls + & I am indifferent & $\begin{array}{c}100 \text { black and red balls } \\
\text { in unknown color ratio }\end{array}$ \\
\hline 21. & 100 black balls & $\begin{array}{c}\text { I am indifferent } \\
\text { between the two urns. }\end{array}$ & $\begin{array}{l}100 \text { black and red balls } \\
\text { in unknown color ratio }\end{array}$ \\
\hline
\end{tabular}

Choices are incentivized with the random-lottery method 12 In the written instructions at the beginning of the experiment, participants are informed that each decision situation is equally likely to be selected for payment. A subject earns the prize of $€ 15$ if, for the relevant decision situation, a ball of his/her preferred color is drawn, otherwise he/she earns nothing. The payment procedure takes place publicly at the end of the experiment and subjects are informed about it at the beginning of the experiment.

\subsubsection{Choice Predictions}

For our decision task, models of decision making under uncertainty that can be reduced to (the equivalent of) single prior models, predict that an individual should choose option $I$ at most once in all decision situations. Specifically, this option should be chosen only when being

\footnotetext{
${ }^{11}$ Note that option $I$ is neither a default option nor the status-quo and, hence, the well known biases relating to these concepts cannot be a reason for participants to eventually choose this option (see, e.g., Kahneman, 2003; Camerer, 2003; Camerer et al., 2011).

${ }^{12}$ See http://people.few.eur.nl/wakker/miscella/debates/randomlinc.htm for a discussion on the appropriateness of the random-lottery incentives scheme.
} 
truly indifferent between the risky and the ambiguous prospect. Note, however, that indifferent individuals may also choose Urn A or Urn B. We divide these models in three classes and discuss them in what follows.

Subjective Expected Utility Theory. Subjective Expected Utility theory (SEU, Savage 1954) models decision making under uncertainty with an expected utility representation, where unknown probabilities are replaced by subjective priors on the ambiguous event. It is straightforward, that according to SEU theory, a participant would choose option $I$ if and only if the winning probability of the risky prospect equals her subjective prior on the ambiguous event. Thus, SEU predicts that option $I$ is chosen at most once.

Uncertainty Aversion. The models in this class are based on the idea that the decision maker has standard preferences, but may hold multiple priors on the ambiguous event and may be averse to ambiguity. The seminal work of David Schmeidler initiated this approach (see Schmeidler 1989 and Gilboa and Schmeidler 1989), and more recently Cerreia-Vioglio et al. (2011) provided a representation result that allows to unify these models. For illustration purposes, we discuss only $\alpha$-Maxmin Expected Utility theory (Ghirardato et al., 2004), but the derived result hold for the whole class of models. According to this theory, the expected utility of a prospect is given by the $\alpha$-weighted sum of the worst and best possible scenario, with $\alpha$ capturing the DM's aversion to ambiguity. That is, although priors can be multiple, decision making is based on a unique representation of the ambiguous prospect. As a consequence, it is predicted that subjects choose option $I$ at most once 13

Cumulative Prospect Theory. Prospect Theory (Kahneman and Tversky, 1979) and its extension, Cumulative Prospect Theory (CPT, Tversky and Kahneman 1992) for decision making under risk and uncertainty, introduce the idea that individuals' choices under uncertainty are best described by allowing for decision weights, that apply to both objective and subjective probabilities. In our decision task, in a given decision situation, an individual may choose option $I$ when the risky and the ambiguous event receive equal decision weight. That is, when being truly CPT-indifferent between the risky and ambiguous prospects. Moreover, option I may be chosen in several decision situations if and only if the winning probabilities of different risky prospects receive equal decision weight 14 Stated differently, a participant may choose option $I$ more than once only if she is sufficiently insensitive to likelihood changes. In order to investi-

\footnotetext{
${ }^{13}$ For a formal proof, see Appendix $\mathrm{A}$

${ }^{14}$ For a formal proof, see Appendix $\mathrm{A}$.
} 
gate this possibility we implement a choice task that allows estimating CPT parameters at the individual level.

\subsection{Part 2 - Lottery Task}

In this part of the experiment we elicit participants' certainty equivalents for 33 lotteries (see Table 2). For each lottery subjects see a computer screen that contains a description of the lottery and a list of 20 equally spaced sure amounts, ranging from the lottery's high to its low potential outcome. In each row of the list subjects have to make a choice between the lottery and the sure amount. In order to facilitate comprehension, the lottery odds are expressed both in percentage points and with the aid of a pie chart 15 Certainty equivalents are calculated as the arithmetic mean of the smallest sure amount preferred to the lottery and the consecutive sure amount in the list.

Table 2: Lotteries used in Lottery Task

\begin{tabular}{crrrrrrrr}
\hline \hline$p_{1}$ & $x_{1}$ & $x_{2}$ & $p_{1}$ & $x_{1}$ & $x_{2}$ & $p_{1}$ & $x_{1}$ & $x_{2}$ \\
\hline 0.05 & 10 & 0 & 0.35 & 25 & 10 & 0.65 & 20 & 5 \\
0.05 & 20 & 5 & 0.45 & 10 & 0 & 0.65 & 25 & 10 \\
0.05 & 25 & 10 & 0.45 & 20 & 5 & 0.75 & 10 & 0 \\
0.1 & 5 & 0 & 0.45 & 25 & 10 & 0.75 & 20 & 5 \\
0.1 & 10 & 5 & 0.5 & 5 & 0 & 0.75 & 25 & 10 \\
0.1 & 25 & 0 & 0.5 & 20 & 5 & 0.9 & 5 & 0 \\
0.25 & 10 & 0 & 0.5 & 25 & 10 & 0.9 & 10 & 5 \\
0.25 & 20 & 5 & 0.55 & 20 & 5 & 0.9 & 25 & 0 \\
0.25 & 25 & 10 & 0.55 & 25 & 10 & 0.95 & 10 & 0 \\
0.35 & 10 & 0 & 0.55 & 10 & 0 & 0.95 & 20 & 5 \\
0.35 & 20 & 5 & 0.65 & 10 & 0 & 0.95 & 25 & 10 \\
\hline $\begin{array}{l}\text { Note: } \\
\text { ability }\end{array}$ of winning $€ x_{2}$ is $1-p_{1}$. & & &
\end{tabular}

In order to determine subjects' payment for this part, at the end of the experiment one decision screen and one row within the decision screen, are randomly selected. The relevant lottery is then publicly played out and earnings are added to those of the first part.

\footnotetext{
${ }^{15} \mathrm{~A}$ screen shot of the computer display can be found in Appendix C
} 


\subsection{Part 3 - Questionnaires}

In the last part of the experiment we ask participants some questions measuring the ability of cognitive reflection and psychological constructs like analytical-rational processing and confidence in intuitive abilities. Specifically, we administered the Cognitive Reflection test (Frederick, 2005) and the Rational-Experiential Inventory (Epstein et al., 1996). In addition we asked questions about personal characteristics (age, gender, etc.) and how they experienced the experiment. Details on the questionnaires can be found in Appendix C.

\subsection{Procedures}

The computerized experiment was conducted at the Behavioral and Experimental Lab (BEElab) at Maastricht University, using the Z-Tree software (Fischbacher, 2007). Upon entering the BEElab, participants were randomly assigned to computer cubicles and not allowed to communicate in any way. Of the 55 participants $90 \%$ were enrolled Maastricht University's School of Business and Economics and $60 \%$ of them were male. The average age was 23 years. The experiment lasted on average 90 minutes and the average earnings per subjects were $€ 32.95$. After all parts have been finished earnings were determined as described above and paid out confidentially.

\subsection{Results}

For convenience, in what follows participants' choices in Part 1 of the experiment are recoded and analyzed as if red had been the selected winning color of each participant 16

We first explore if the choice pattern of our participants, when choosing between risky and ambiguous prospects, is consistent with behavior reported in the literature. We find that the risky prospect is chosen by the large majority of participants as long as the winning probability is at least 0.5 , whereas the ambiguous prospect is the most common choice in all decision situations where the winning probability of the risky prospect is at most 0.4. Ignoring choices in favor of option $I$, we use binomial tests to verify for each decision situation separately, whether the risky or ambiguous prospect is chosen by the majority of participants. We find that the likelihood of choices favoring the risky prospect is significantly larger than $50 \%$ at the $1 \%$ significance level in all decision situations characterized by a winning probability of at least 0.5. On the

\footnotetext{
${ }^{16}$ To preclude that results are due to noise and/or incomprehension we exclude from the analysis all participants who made (weakly) dominated choices in the first and last decision situation, such as choosing the ambiguous prospect instead of the sure payment or choosing to earn nothing for sure instead of selecting the ambiguous prospect. This leaves us with 35 observations. In Appendix E we report an analysis using data of all participants and find that the results are qualitatively the same. Note also that excluding participants who have made such choices makes the case for incompleteness more difficult as such behavior arguably is a reflection of incompleteness.
} 
other hand, choices favoring the ambiguous prospect are significantly more likely than $50 \%$ at the $1 \%$ significance level in all choice situations characterized by a winning probability $p \leq 0.4$. In the decision situations where the winning probability of the risky prospect is equal to 0.45 , the number of individuals choosing the risky prospect is not significantly different from the number choosing the ambiguous one $(p$-value $=0.19)$. Consistent with the large body of results reported in the literature (see Camerer and Weber, 1992 for a review), these results thus indicate that subjects are moderately averse to ambiguity. This gives us confidence in that our pool of participants is similar to most other subject pools.

We now turn to our main research question and analyze choices in favor of option $I$. Our first result in that respect is that the choice of option $I$ is very frequent. When the winning probability of the risky prospect, $p$, is equal to 0.35 almost one third of the participants $(29 \%)$ choose option $I$. Further, when $0.5 \leq p \leq 0.4$, the relative majority of participants (40\%) choose option $I$, and when $p=0.5520 \%$ of the participants choose $I$. These figures already suggest that some individuals choose option $I$ more than once.

This impression is corroborated by the histogram in Figure 1, which reports the relative frequency of participants who choose option $I n$ times. Specifically, only $23 \%$ of the subjects never select option $I$ and $29 \%$ select it exactly once. The remaining $48 \%$ of participants choose option $I$ in at least two decision situations and more than $35 \%$ choose option $I$ at least three times. Further, of those participants who choose option $I$ more than once, $83 \%$ do so in consecutive decision situations.

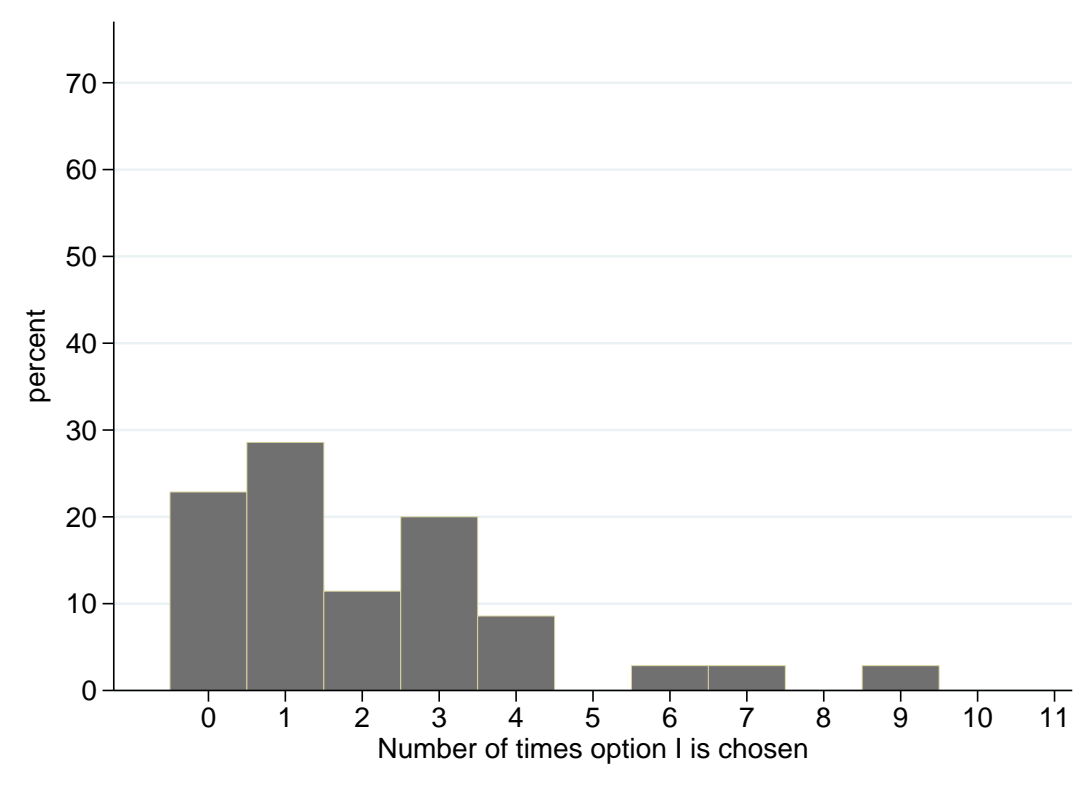

Figure 1: Risk-Ambi - Relative frequency of participants choosing option $I n$ times. 
To summarize, contrary to the predictions of the discussed decision making models, we find that almost half of the participants choose option $I$ more than once. This suggests that preferences of these individuals' are incomplete when choosing between risky and ambiguous prospects. However, as discussed in the previous section, when individuals are sufficiently insensitive to likelihood changes, CPT may also account for such behavior. We address this possibility in the following section.

Cumulative Prospect Theory. To test if likelihood insensitivity can explain repeated choices of option $I$, we use the choice data of the second part of the experiment and estimate CPT parameters at the individual level. For these estimations we need to choose specific functional forms, both for the value function $v(x)$ and probability weighting function $w(p)$, that combine parsimony with good data fit. For the value function it has been shown that a simple power function $v(x)=x^{\alpha}, \alpha>0$ is a good compromise between these requirements (Wakker, 2008; Bruhin et al., 2010). For probability weighting we adopt the function originally proposed by Prelec (1998):

$$
w(p)=\exp \left(-(-\ln p)^{\gamma}\right) \quad 0<\gamma<1
$$

Like in the original formulation of prospect theory Kahneman and Tversky (1979), w(p) has an inverted S-shape which implies that small probabilities are over-weighted and large probabilities are under-weighted. The degree of deviation from linearity is conveniently captured by the single parameter $\gamma$, where smaller values refer to larger deviations. The function has been used in several empirical applications (see, e.g., Gonzalez and Wu, 1999; Bruhin et al., 2010; Epper et al., 2011).

We jointly estimate the parameter values of $\alpha$ and $\gamma$ at the individual level by minimizing the sums of squared distances between the predicted and observed certainty equivalents. To correct for heteroscedasticity, lottery outcomes are normalized 17

Recall that CPT can be used to explain repeated choices of option $I$ if and only if the winning probabilities of different risky prospects receive the same decision weight. Empirically, we see that most choices of option $I$ occur for winning probabilities between 0.35 and 0.50 of the risky options. Applying the probability weighting function (11) it can be shown that $\gamma \leq 0.2$ is needed to ensure that the difference in probability weights for consecutive decision situations is about 0.01 or lower, for probabilities in the interval 0.25 to 0.6 . Put differently, probability weighting can explain repeated choices of option $I$ only if $\gamma$ is not larger than 0.2 . We find that the average

\footnotetext{
${ }^{17}$ The calculation of certainty equivalents in the lottery choice tasks (in Part 2 of the experiment) requires a unique switching point from the sure amount to the lottery. We did not impose this restriction on participants' behavior in the experiment and do observe sometimes multiple switching points. In these cases we use the most risk averse certainty equivalent.
} 
value of $\gamma$ among subjects who choose option $I$ more than once is 0.39 , which is significantly above the threshold value of 0.2 (Wilcoxon test $p$-value $<0.01$ ) 18 Moreover, out of the 17 participants who repeatedly choose option $I$ only 3 have an estimated $\gamma \leq 0.2$. Hence, we conclude that likelihood insensitivity cannot explain the observed repeated choices of option $I$.

Our results so far show that about 50 percent of the participants repeatedly choose option $I$, which is (1) inconsistent with prominent models of decision making under risk and uncertainty (subjective expected utility, uncertainty aversion) and (2) cannot be explained by participants' insensitivity to likelihood changes. Although suggestive for incomplete preferences due to multiple priors, one might argue that the repeated choice of option $I$ is actually reflecting choice mistakes (probabilistic choice or 'thick' indifference curves). In the next section we describe an experiment designed to test this hypothesis.

\section{Experiment Risk-Sure - The Role of Mistakes}

Probabilistic choice models are based on the idea that individuals make choice mistakes and, thus, when confronted with two options do not necessarily choose the one that maximizes their utility. The likelihood of making a mistake is a function of the expected utility difference between the available options: the larger the expected utility difference, the lower the probability of choosing the dominated option. The first model of this kind was proposed by Luce (1959), and applications in its spirit appear, for instance, in Harless and Camerer (1994) and Hey and Orme (1994). According to this approach, the choice of option $I$ in experiment Risk-Ambi could be the result of mistakes, which are more likely when the expected utility difference between the risky and the ambiguous prospect is perceived as small.

In order to test whether the repeated choice of option $I$ is consistent with this interpretation, we run an additional experiment with 50 subjects. Participants have to make choices between risky prospects as in Risk-Ambi (see Table 1) but the ambiguous prospect is replaced by a sure payment of $€ 7.50$. Option $I$ is also available, and if chosen, it entails that either the risky prospect or the certain payment is assigned to the subject with equal probability.

If mistakes would be a good explanation for the behavior observed in Risk-Ambi, we should observe that option $I$ is also frequently and repeatedly chosen in Risk-Sure. For risk neutral and weakly risk averse or risk seeking participants, option $I$ should then be chosen most often for winning probabilities around 0.50. Note, however, that due to the nature of the decision situations, participants always face some decision situations where the utility difference between the risky option and the certain payment is very small, irrespective of their actual risk preferences.

\footnotetext{
${ }^{18}$ The average estimated value of $\alpha$ is 0.88 .
} 


\section{$4.1 \quad$ Results}

Figure 2 depicts the relative frequency of choices in favor of option $I, 19$ It shows that 90 percent of the participants choose option $I$ at most once. This is in stark contrast to the observation in Risk-Ambi where this was the case for only 51 percent. Hence, in Risk-Sure only very few participants exhibit mistakes or thick indifference curves, which makes mistakes due to small utility differences an unlikely explanation for the repeated choice of option $I$ observed in RiskAmbi. Note, that the infrequent choice of option I in Risk-Sure also corroborates our finding, reported further above, that decision weighting cannot account for the frequent choice of option $I$ in Risk-Ambi.

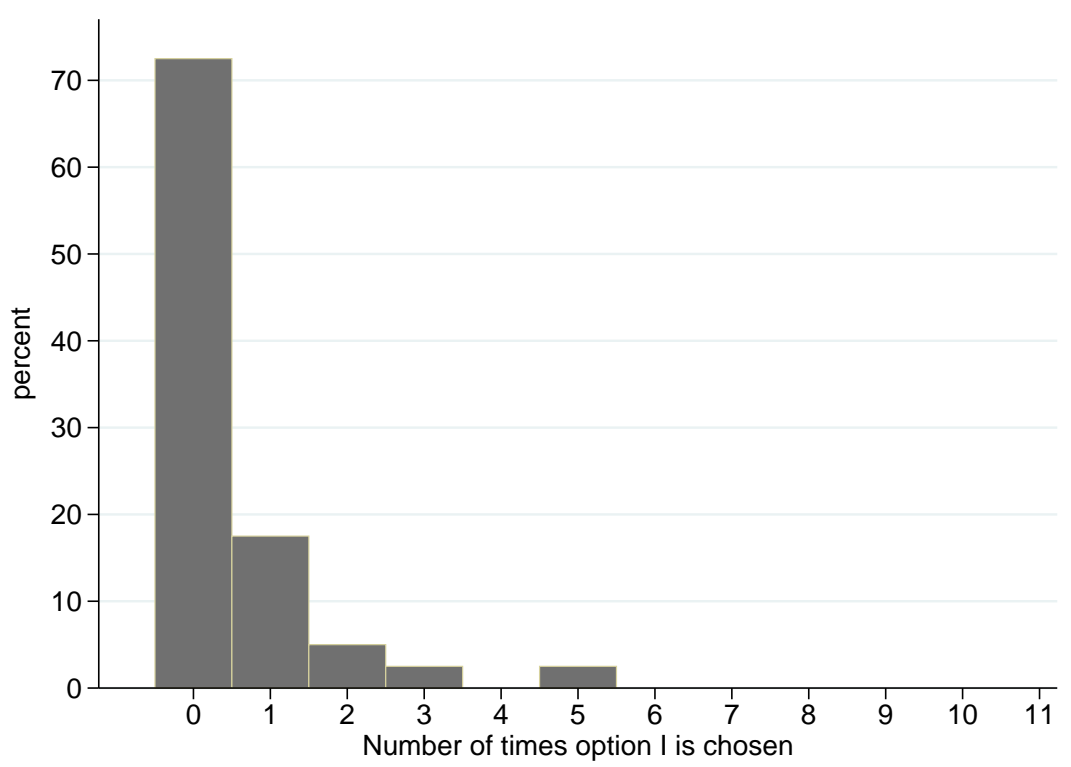

Figure 2: Risk-Sure - Relative frequency of participants choosing option $I n$ times.

\section{Experiment Risk-Ambi-high - Robustness and Comparative Statics Based on Incomplete Preferences}

The purpose of our third experiment is to test (1) whether repeatedly choosing option $I$ is robust against a change in incentives, and (2) whether this behavioral regularity is consistent with the existence of an incomplete preference relation between prospects. To this end we conduct an experiment that is exactly the same as Risk-Ambi, described in Section 3, except that the prize of the ambiguous prospect is now increased by one-third (i.e., $€ 5$ ) and is thus equal to $€ 20$.

\footnotetext{
${ }^{19}$ Applying the same criteria as in Risk-Ambi, we excluded from the analysis 10 subjects that choose a weakly dominated option.
} 
Regarding robustness, we expect that also in Risk-Ambi-high a large percentage of participants will choose option $I$ repeatedly. In addition, if repeated choice of option $I$ is an expression of incomplete preferences due to multiple priors on ambiguous prospects, we can formulate the following hypotheses. In comparison to Risk-Ambi, option $I$ is more often chosen in Risk-Ambihigh (H1). Moreover, the decision situations where option $I$ is most frequently chosen differ between Risk-Ambi and Risk-Ambi-high. Specifically, we expect that in Risk-Ambi-highthese decision situations are characterized by higher winning probabilities of the risky prospects (H2) 20 In the following we develop the argument more formally.

We assume that (expected) utility in money $u($.$) is strictly increasing and w.l.o.g. normalize$ $u(0)=0$. Let $p$ denote the winning probability of a risky prospect, $x>0$ the prize in case of good luck and 0 the prize in case of bad luck (cf. Table 1). A subject may have multiple priors on the ambiguous event and we denote with $w$ and $b$ the subject's worst and best (winning) prior on the ambiguous event, respectively. In Risk-Ambi incomplete preferences due to multiple priors imply that for some $p \in[0,1]$ and $q \in] w, b], p u(x) \leq q u(x)$, and the subject would weakly prefer the ambiguous event, whereas for the same $p$ but another (smaller) $q^{\prime} \in[w, b], p u(x)>q^{\prime} u(x)$, and the subject would prefer the risky event. Preferences are complete and the ambiguous (risky) prospect is chosen when the expected utility of the ambiguous prospects calculated for $w(b)$ is larger (smaller) than the expected utility of the risky prospect.

Assume for convenience that the winning probabilities of a risky prospect in our experiments change continuously (and not in steps of 0.05). Denote with $p_{1}^{w}$ the winning probability in experiment Risk-Ambi such that the risky prospect in expectations gives the same outcome as the ambiguous prospect with the worst prior applied. That is, $p_{1}^{w} u(x)=w u(x)$, implying $p_{1}^{w}=w$. Similarly, denote with $p_{1}^{b}$ the winning probability in experiment Risk-Ambi such that the risky prospect gives the same expected outcome as the ambiguous outcome with the best prior applied: $p_{1}^{b} u(x)=b u(x)$, implying $p_{1}^{b}=b$.

In experiment Risk-Ambi-high the prize for the ambiguous event is increased with $y>0$. The new prize is $x+y>x$, implying that $p_{1}^{w} u(x)<w u(x+y)$. Thus, in this experiment, for $p_{3}^{w} u(x)=w u(x+y)$ to hold it is necessary that $p_{3}^{w}>p_{1}^{w}=w$. Similarly, the higher prize implies that $p_{1}^{b} u(x)<b u(x+y)$ and for $p_{3}^{b} u(x)=b u(x+y)$ to hold it is necessary that $p_{3}^{b}>p_{1}^{b}=b$. Hence, measured in probabilities of the risky event, in Risk-Ambi-high the interval of multiple priors should be shifted to higher winning probabilities than in Risk-Sure. This implies that if repeated choices of option $I$ indeed reflect incomplete preferences due to multiple priors on the ambiguous

\footnotetext{
${ }^{20} \mathrm{~A}$ necessary assumption for this prediction is that participants in Risk-Ambi and Risk-Ambi-high hold on average the same prior beliefs on the ambiguous event. As the subject pool as well as all procedural details are the same in all experiments there is no good reason for why this assumption should not hold.
} 
event, we should observe these choices at higher winning probabilities in Risk-Ambi-high than in Risk-Ambi (cf. H2).

For the hypothesis that in Risk-Ambi-high option I tends be chosen more often than in Risk$A m b i$ (cf. H1), it is necessary to show that the interval of multiple priors, measured in winning probabilities of the risky prospect, is wider in Risk-Ambi-high than in Risk-Ambi, i.e, $p_{1}^{b}-p_{1}^{w}<$ $p_{3}^{b}-p_{3}^{w}$. It is easily shown that this is indeed the case. Recall that $p_{1}^{b}=b$ and $p_{1}^{w}=w$ and suppose to the contrary that $p_{1}^{b}-p_{1}^{w}=b-w \geq p_{3}^{b}-p_{3}^{w}$ and, hence, $b u(x)-w u(x) \geq p_{3}^{b} u(x)-p_{3}^{w} u(x)$. From $p_{3}^{b} u(x)=b u(x+y)$ and $p_{3}^{w} u(x)=w u(x+y)$ it follows that $[b-w] u(x) \geq[b-w] u(x+y)$ in contradiction to the strict monotonicity of $u($.$) .$

To illustrate in terms of the experiments, consider that a subject holds the set of priors $[0.33,0.47]$. In Risk-Ambi, this subject may thus choose option $I$ for risky decision situations characterized by winning probabilities $p \in\{0.35,0.40,0.45\}$. In Risk-Ambi-high, a 'twin' subject holding the same set of prior beliefs may instead choose option $I$ for risky decision situations characterized by winning probabilities $p \in\{0.45,0.50,0.55,0.60\}$.

For experiment Risk-Ambi-high we applied the same procedures as for the other two experiments and recruited 53 students from Maastricht University. Subjects who took part in Risk-Ambi or Risk-Sure were not allowed to participate. The experiment lasted on average 90 minutes and the average earnings per subjects were $€ 28.70$.

\subsection{Results}

Subjects' choices in Risk-Ambi-high reveal that the results obtained in Risk-Ambi are robust 21 For the moment ignoring choices of option $I$, the risky prospect is chosen by more than $50 \%$ of the subjects in all decision situations characterized by $p \geq 0.55$ ( $p$-value $\leq 0.01$, two sided binomial test). Conversely, the ambiguous prospect is chosen by more than $50 \%$ of the subjects in all decision situations where $p \leq 0.45(p$-value $<0.01)$. In the decision situation where $p=0.50$, the number of individuals choosing the risky prospect is not significantly different from the number choosing the ambiguous one $(p-$ value $=0.24)$.

More interestingly, Figure 3 shows a histogram of the relative frequency of option $I$ in RiskAmbi-high (cf. Figure 1 for Risk-Ambi). It shows that about only 40 percent of the participants choose option $I$ at most once, whereas the remaining subjects choose it in at least two decision situations. This data thus confirm that the repeated choice of option $I$ is robust against increases in the prize of the ambiguous prospect.

\footnotetext{
${ }^{21}$ As in the other experiments, we exclude from the analysis all subjects that made dominated choices in the first and last decision situation. This leaves us with 38 observations.
} 


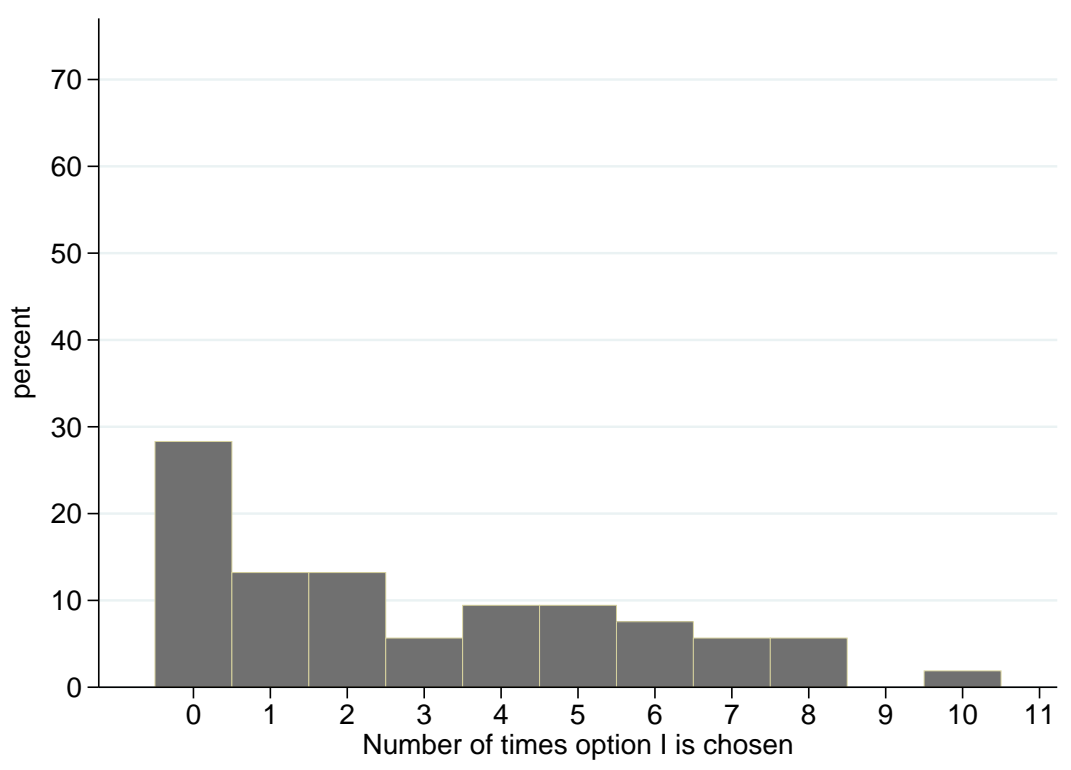

Figure 3: Risk-Ambi-high - Relative frequency of participants choosing option $I n$ times.

When comparing participants' choices in the two experiments, we find qualitative support for H1. Consistent with the incomplete preferences model participants choose option $I$ more often in Risk-Ambi-high (2.6 times on average) than in Risk-Ambi (2.1 times on average). However, the difference fails to reach statistical significance, which may be due to a too small prize change.

The comparative statics hypothesis H2 is supported qualitatively and quantitatively. Figure 4 shows how choices of option $I$ are distributed over the decision situations in the two experiments. Compared to Risk-Ambi, in Risk-Ambi-high, option $I$ is most common in decision situations characterized by a higher winning probability of the risky prospect, as predicted. To test whether this change in behavior is statistically significant, we conduct chi-square tests for every decision situation and test the hypothesis that option $I$ is chosen more often in Risk-Ambi-high than in Risk-Ambi. These tests indeed show that in Risk-Ambi-high significantly more subjects choose option $I$ in the decision situations characterized by $p_{60}$ and $p_{55}(p$-value $=0.05$ and 0.04 , respectively), whereas differences are statistically insignificant in all other decision situations $(p$-values $>0.16)$.

In sum, experiment Risk-Ambi-high thus shows that the repeated choice of option $I$ is a robust phenomenon and that choices are consistent with the comparative statics predictions of a model of multiple priors for the ambiguous event. This strongly suggests that the repeated choice of option $I$ indeed reveals incomplete preferences under uncertainty. 


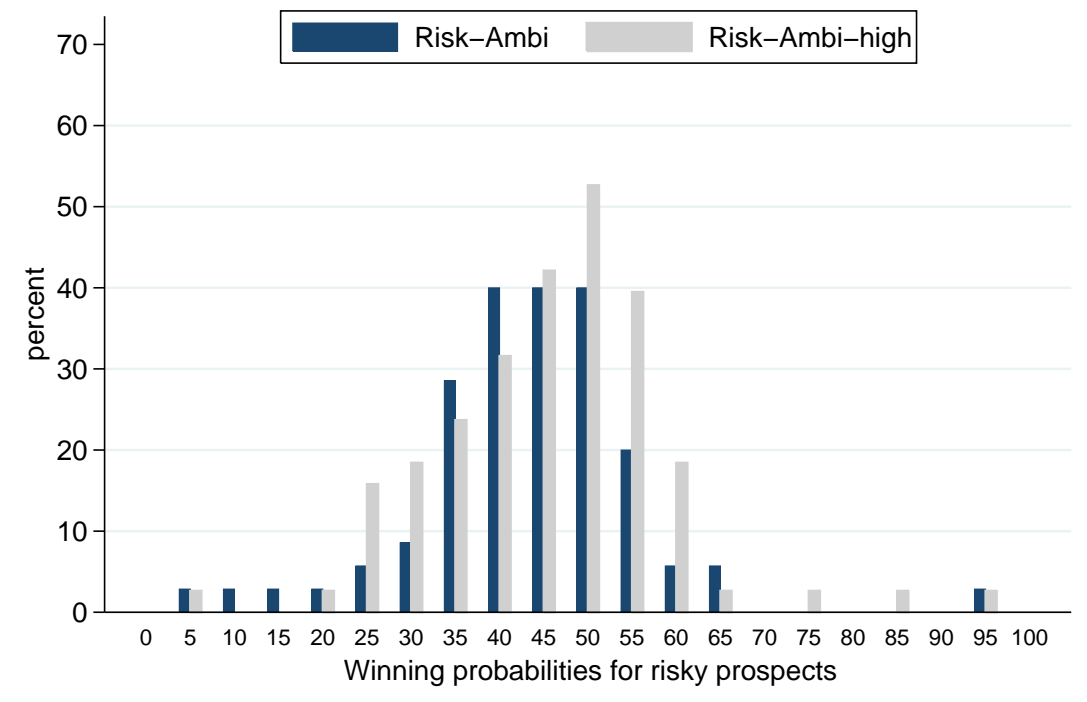

Figure 4: Frequencies of choices of option $I$ in Risk-Ambi and Risk-Ambi-high.

\section{Discussion and Conclusions}

The completeness axiom has been identified as a questionable assumption of economic decision making models and in response a number of theoretical models relaxing it have been developed. However, empirical evidence on actual incompleteness of preferences is difficult to gather as such evidence has to come from observed choices. In this paper we propose a series of laboratory experiments with the aim to reveal whether preferences may be incomplete under uncertainty (Gilboa et al., 2010). Our empirical strategy is to create a choice environment that allows us to interpret behavior to be either consistent with classes of decision models, both normative and descriptive, that assume completeness or with incomplete preferences due to multiple priors over an ambiguous event.

We find that approximately half of the studied subjects display a choice pattern that is inconsistent with models that allow for a single representation of the ambiguous prospect, choice errors and decision weights, but can be explained by the existence of incomplete preference relations. Indeed, consistent with an inability to pairwise rank choice options, subjects repeatedly delegate their choices to a randomization device. The interpretation that the observed pattern is due to incompleteness finds also support in psychological literature on decision making. There it has been shown that people like to be able to justify their choices, to themselves and to others (Simonson, 1989; Shafir et al., 1993). When preferences are incomplete it may be hard to justify to select one prospect over the other and relegating the choice to some external device seems appealing. 
The possibility to delegate choice to a randomization device relates our study to a few recent empirical papers investigating a possible preference for randomization. Dominiak and Schnedler (2011) experimentally investigate the relationship between randomization-loving and uncertaintyaversion. They find that these are not negatively associated and that a non-negligible minority of subjects are even randomization-averse. More closely related to our study, Dwenger et al. (2014) conduct experiments where individuals have to choose between (sets of) vouchers twice, where each choice is implemented with a certain known probability. In one treatment subjects can also explicitly choose to randomize their choices. The authors find that a fraction of choices is implicitly consistent with a preference for randomization and that it increases when the randomization possibility is explicit.

To explain their observations the authors propose a theoretical framework in the spirit of regret theory (Loomes and Sugden, 1982). The key assumptions are that decision makers may be responsibility averse and that randomization allows them to minimize anticipated regret feelings associated with choice responsibility. This framework may also be used to explain our results when subjects have to choose between risky and ambiguous prospects (experiments Risk-Ambi and Risk-Ambi-high). For that it needs to be assumed, however, that choosing option $I$ relieves the decision maker from anticipatory feelings of regret and rejoice. That is, the active choice of the randomization devise should not be affected by any feelings of regret and rejoice, whereas an active choice for the risky or ambiguous prospect will be affected. If one is willing to make this assumption, it would imply that subjects should have a preference for randomization also when they have to choose between risky prospects and certain payments 22 However, this is not the case, as we have seen in our experiment Risk-Sure where subjects hardly ever choose option I (see Section (4). Thus, anticipated regret feelings do not appear to be a satisfactory explanation of the choice pattern observed in our experiments.

We note that our interpretation of the results should not be considered as a contradiction to the explanations put forward in Dwenger et al. (2014). For one because we consider choices and preferences under uncertainty, whereas Dwenger et al. (2014) explore decisions under risk. We would rather suggest that incomplete preferences due to indecisiveness in taste (like in Ok et al., 2012) may be an alternative framework to understand their results.

Incomplete preferences are also invoked as a plausible explanation for the results in Agranov and Ortoleva (2013). The authors use a series of experiments to demonstrate that

\footnotetext{
${ }^{22}$ Specifically, it can be shown that, under the assumption that actively choosing option $I$ does not lead to regret-rejoice whereas active choice of the risky or ambiguous prospect does, to rationalize (repeated) choice of option $I$ in Risk-Ambi it is necessary that regret feelings are sufficiently stronger than rejoice feelings. If this is the case it can be further shown that repeated choice of $I$ should also be observed in Risk-Sure. See Appendix B for a formal derivation of these statements.
} 
stochastic choices can be deliberate instead of mistaken. They discuss the behavior observed in their experiments in light of the model by Cerreia-Vioglio et al. (2015), in which the decision maker can be characterized by a set of possible utility functions over outcomes. When the decision maker does not know which function she should maximize, a randomization device may be strictly preferred to a deterministic choice. Our results suggest that delegation to a chance device may also be 'optimal' when choices involve uncertain prospects. Moreover, our design allows to interpret this behavior as due to incomplete preferences under uncertainty, as we show the inadequacy of decision making models that assume completeness.

Decision making models relaxing the completeness axiom have proposed specific decision rules that guide choice behavior when options cannot be ranked. In Gilboa et al. (2010), for example, the model's axioms imply that maxmin is employed when preferences are incomplete. We want to emphasize that, although our experiments suggest that subjects may revert to randomization in case of incompleteness, we do not intend to test which decision rule individuals actually employ. Rather, our aim is to provide empirical evidence on the actual existence of incomplete preference relations under uncertainty.

We show that incomplete preferences - next to being a theoretically possible and intuitively appealing concept - can also be revealed. Our approach also shows that not all people exhibit incomplete preferences under uncertainty as some appear to be less indecisive than others. In future research, a more refined version of our experiments may even allow for discriminating between different types of decision makers with incomplete preferences. Such a categorization could then be used for determining the accurate model and for making accurate predictions on an individual level.

Guided by the work of Gilboa et al. (2010), we would like to conclude with a reflection on the rationality of the observed choice pattern. These authors propose that a decision maker can make two types of choices. Objective rational choices are such that the decision maker could convince others that she is right in making them, while choices are subjectively rational when the decision maker cannot be convinced that she is wrong when making them. These two notions of rationality are directly related to the completeness axiom: when preferences are incomplete because of uncertainty, an objectively justifiable choice may not exists, but subjective rationality eventually guides choice behavior. The repeated choice of option $I$ seems consistent with this notion of subjective rationality and it may be interesting to theoretically explore whether such a decision rule could be axiomatically derived. 


\section{References}

Aad, G., Abajyan, T., Abbott, B., Abdallah, J., Khalek, S. A., Abdelalim, A., Abdinov, O., Aben, R., Abi, B., Abolins, M., et al. (2012). Observation of a new particle in the search for the standard model higgs boson with the atlas detector at the lhc. Physics Letters B, $716(1): 1-29$.

Agranov, M. and Ortoleva, P. (2013). Stochastic choice and hedging. Mimeo, California Institute of Technology.

Alang, N. (2015). Using the untested Ebola drug in Ebola affected patients: An ethical dilemma. International Journal of Travel Medicine and Global Health, 3(1):1.

Aumann, R. J. (1962). Utility theory without the completeness axiom. Econometrica, 30(3):445462.

Bewley, T. (2002). Knightian decision theory. Part I. Decisions in Economics and Finance, 25(2):79-110.

Bossaerts, P., Ghirardato, P., Guarnaschelli, S., and Zame, W. R. (2010). Ambiguity in asset markets: Theory and experiment. Review of Financial Studies, 23(4):1325-1359.

Bruhin, A., Fehr-Duda, H., and Epper, T. (2010). Risk and rationality: Uncovering heterogeneity in probability distortion. Econometrica, 78(4):1375-1412.

Camerer, C. and Weber, M. (1992). Recent developments in modeling preferences: Uncertainty and ambiguity. Journal of Risk and Uncertainty, 5(4):325-370.

Camerer, C. F. (2003). Behavioral game theory: Experiments in strategic interaction. Princeton University Press, Princeton, NJ.

Camerer, C. F., Loewenstein, G., and Rabin, M. (2011). Advances in behavioral economics. Princeton University Press, Princeton, NJ.

Cerreia-Vioglio, S., Dillenberger, D., and Ortoleva, P. (2015). Cautious expected utility and the certainty effect. Econometrica, 83(2):693-728.

Cerreia-Vioglio, S., Maccheroni, F., Marinacci, M., and Montrucchio, L. (2011). Uncertainty averse preferences. Journal of Economic Theory, 146(4):1275-1330.

Cohen, M., Jaffray, J.-Y., and Said, T. (1987). Experimental comparison of individual behavior under risk and under uncertainty for gains and for losses. Organizational Behavior and Human Decision Processes, 39(1):1-22. 
Danan, E. and Ziegelmeyer, A. (2006). Are preferences complete? An experimental measurement of indecisiveness under risk. Working paper, Max-Planck-Institute for Research into Economic Systems, Strategic Interaction Group, Jena.

Dominiak, A. and Schnedler, W. (2011). Attitudes toward uncertainty and randomization: An experimental study. Economic Theory, 48(2-3):289-312.

Dubra, J., Maccheroni, F., and Ok, E. (2004). Expected utility theory without the completeness axiom. Journal of Economic Theory, 115(1):118-133.

Dwenger, N., Kübler, D., and Weizsacker, G. (2014). Flipping a coin: Theory and evidence. CESifo Working Paper Series No. 4740, CESifo Munich.

Eliaz, K. and Ok, E. (2006). Indifference or indecisiveness? Choice-theoretic foundations of incomplete preferences. Games and Economic Behavior, 56(1):61-86.

Epper, T., Fehr-Duda, H., and Bruhin, A. (2011). Viewing the future through a warped lens: Why uncertainty generates hyperbolic discounting. Journal of Risk and Uncertainty, 43(3):169-203.

Epstein, S., Pacini, R., Denes-Raj, V., and Heier, H. (1996). Individual differences in intuitiveexperiential and analytical-rational thinking styles. Journal of Personality and Social Psychology, 71(2):390.

Fischbacher, U. (2007). z-Tree: Zurich toolbox for ready-made economic experiments. Experimental Economics, 10(2):171-178.

Frederick, S. (2005). Cognitive reflection and decision making. The Journal of Economic Perspectives, 19(4):25-42.

Ghirardato, P., Maccheroni, F., and Marinacci, M. (2004). Differentiating ambiguity and ambiguity attitude. Journal of Economic Theory, 118(2):133-173.

Gilboa, I., Maccheroni, F., Marinacci, M., and Schmeidler, D. (2010). Objective and subjective rationality in a multiple prior model. Econometrica, 78(2):755-770.

Gilboa, I. and Schmeidler, D. (1989). Maxmin expected utility with non-unique prior. Journal of Mathematical Economics, 18(2):141-153.

Gonzalez, R. and Wu, G. (1999). On the shape of the probability weighting function. Cognitive Psychology, 38(1):129-166. 
Harless, D. W. and Camerer, C. F. (1994). The predictive utility of generalized expected utility theories. Econometrica, 62(6):1251-1289.

Hey, J. D. and Orme, C. (1994). Investigating generalizations of expected utility theory using experimental data. Econometrica, 62(6):1291-1326.

Kahneman, D. (2003). Maps of bounded rationality: Psychology for behavioral economics. American Economic Review, 93(5):1449-1475.

Kahneman, D. and Tversky, A. (1979). Prospect theory: An analysis of decision under risk. Econometrica, 47(2):263-291.

Kraus, A. and Sagi, J. S. (2006). Inter-temporal preference for flexibility and risky choice. Journal of Mathematical Economics, 42(6):698-709.

Loomes, G. and Sugden, R. (1982). Regret theory: An alternative theory of rational choice under uncertainty. The Economic Journal, 92(368):805-824.

Luce, R. D. (1959). Individual Choice Behavior a Theoretical Analysis. John Wiley and Sons, New York.

Mandler, M. (2004). Status quo maintenance reconsidered: Changing or incomplete preferences? The Economic Journal, 114(499):F518-F535.

Mandler, M. (2005). Incomplete preferences and rational intransitivity of choice. Games and Economic Behavior, 50(2):255-277.

Masatlioglu, Y. and Ok, E. A. (2005). Rational choice with status quo bias. Journal of Economic Theory, 121(1):1-29.

Mukerji, S. and Tallon, J.-M. (2001). Ambiguity aversion and incompleteness of financial markets. The Review of Economic Studies, 68(4):883-904.

Ok, E. (2002). Utility representation of an incomplete preference relation. Journal of Economic Theory, 104(2):429-449.

Ok, E., Ortoleva, P., and Riella, G. (2012). Incomplete preferences under uncertainty: Indecisiveness in beliefs vs. tastes. Econometrica, 80(4):1791-1808.

Ortoleva, P. (2010). Status quo bias, multiple priors and uncertainty aversion. Games and Economic Behavior, 69(2):411-424.

Prelec, D. (1998). The probability weighting function. Econometrica, 66(3):497-527. 
Savage, L. J. (1954). The Foundations of Statistics. Wiley, New York.

Schmeidler, D. (1989). Subjective probability and expected utility without additivity. Econometrica, 57(3):571-587.

Shafir, E., Simonson, I., and Tversky, A. (1993). Reason-based choice. Cognition, 49(1-2):11-36.

Simonson, I. (1989). Choice based on reasons: The case of attraction and compromise effects. Journal of Consumer Research, 16(2):158-174.

Tversky, A. and Kahneman, D. (1992). Advances in prospect theory: Cumulative representation of uncertainty. Journal of Risk and uncertainty, 5(4):297-323.

Wakker, P. (2008). Explaining the characteristics of the power (CRRA) utility family. Health Economics, 17(12):1329-1344.

Wakker, P. (2010). Prospect Theory for Risk and Ambiguity. Cambridge: Cambridge University Press. 


\section{Appendix}

\section{A Models of Decision Making under Uncertainty}

In the following we consider the discussed models of decision making under uncertainty and prove that they cannot account for the repeated avoidance of active choice.

\section{A.1 $\alpha$-maxmin Expected Utility Theory}

Consider $\alpha$ - maxmin expected utility (MEU) theory as in Ghirardato et al. (2004). The decision maker holds a set of priors $C=[\underline{c}, \bar{c}] \subseteq[0,1]$ on the ambiguous event and is characterized by an index $\alpha$ which captures attitude to ambiguity. The index lies in the interval $[0,1]$ and can be viewed as the weight that the decision maker places on the most pessimistic scenario, given his set of prior $C$. The utility function $U(\cdot)$ is the same as assumed in expected utility theory. In our experiment, subjects would evaluate ambiguous prospects as follows:

$$
\alpha-M E U_{a}\left(x_{1}, x_{2} ; q, \alpha\right)=\alpha \min _{q \in[\underline{c}, \bar{c}]}\left[q U\left(x_{1}\right)+(1-q) U\left(x_{2}\right)\right]+(1-\alpha) \max _{q \in[c, \bar{c}]}\left[q U\left(x_{1}\right)+(1-q) U\left(x_{2}\right)\right] .
$$

Where $q$ is the (unknown) winning probability of the ambiguous prospect, $x_{1}$ is the monetary prize equal to $€ 15$ and $x_{2}$ is the $€ 0$ outcome. Since the worst prior is $\underline{c}$ and the best prior is $\bar{c}$ and $U\left(x_{1}\right)\left(U\left(x_{2}\right)\right)$ can be normalized to $1(0)$, the above function is equivalent to:

$$
\alpha-M E U_{a}\left(x_{1}, x_{2} ; q, \alpha\right)=\alpha \underline{c}+(1-\alpha) \bar{c} .
$$

Applying the same normalizations, expected utility from a risky prospect is given by $E U_{r}\left(x_{1}, x_{2} ; p_{r}\right)=p_{r}$. Hence, a subject is indifferent between a risky prospect with winning probability $p_{r}$ and the ambiguous prospect if and only if $E U_{r}\left(x_{1}, x_{2} ; p_{r}\right)=p_{r}=\alpha \underline{c}+(1-\alpha) \bar{c}=\alpha-M E U_{a}\left(x_{1}, x_{2} ; q, \alpha\right)$. As $\alpha$ and $q$ are independent of the winning probability $p_{r}$ of the risky prospect, this implies that option $I$ should be chosen at most once. From that it is also easy to see that any model assuming a decision rule that reduces multiple priors to a single prior allows for at most one choice of option $I$.

\section{A.2 Cumulative Prospect Theory}

Cumulative prospect theory $(\mathrm{CPT})$ as proposed in Tversky and Kahneman (1992) allows for non-linear decision weights. Let $W^{+}\left(p_{r}\right)$ and $W^{+}(A)$ be the decision weighting functions for risky and ambiguous prospects, respectively, and let $v(x)$ be a CPT value function. A decision maker evaluates the ambiguous prospect as

$$
C P T_{a}\left(x_{1}, x_{2} ; A\right)=W^{+}(A) v\left(x_{1}\right)+W^{+}(\neg A) v\left(x_{2}\right) \Leftrightarrow C P T_{a}\left(x_{1}, x_{2} ; A\right)=W^{+}(A) v\left(x_{1}\right),
$$

where $A$ the denotes the winning event and $\neg A$ its complement and the second equation follows (w.l.o.g.) from the normalization $v\left(x_{2}\right):=0$. Similarly, a risky prospect with winning probability $p_{r}$ is evaluated as

$$
C P T_{r}\left(x_{1}, x_{2} ; p_{r}\right)=W^{+}\left(p_{r}\right) v\left(x_{1}\right)+W^{+}\left(1-p_{r}\right) v\left(x_{2}\right) \Leftrightarrow C P T_{r}\left(x_{1}, x_{2} ; p_{r}\right)=W^{+}\left(p_{r}\right) v\left(x_{1}\right) .
$$


It follows that multiple choices of option $I$ for different winning probabilities $p_{i}, p_{i+1}, \ldots, p_{i+k}$ of the risky prospect are CPT rationalizable if and only if

$$
W^{+}(A)=W^{+}\left(p_{i}\right)=W^{+}\left(p_{i+1}\right)=\cdots=W^{+}\left(p_{i+n}\right) .
$$

In other words, multiple choices of option $I$ are possible under CPT if and only if the decision weight function is very flat, at least locally. 


\section{B Anticipated Regret-Rejoice}

Here we first show the conditions under which anticipated regret-rejoice may account for repeated choice of option $I$ in experiment Risk-Ambi, where participants had to choose between different risky prospects, an ambiguous prospect, and option $I$. Thereafter, we derive the conditions for repeated choice of option $I$ in Risk-Sure, where participants had to choose between risky prospects, a sure fixed payment, and option $I$. We will show that an asymmetry of the utility effect of regret and rejoice is a necessary condition for rationalizing the choice of option $I$ in both, Risk-Ambi and Risk-Sure. Therefore, since we observe repeated choice of option I in Risk-Ambi, we should also observe it in Risk-Sure. This is not the case and it is thus - on theoretical grounds - not possible to rationalize repeated choice of option I in Risk-Ambi with anticipated regret-rejoice.

Note first that we need to assume that actively choosing option $I$ does not lead to anticipated regret or rejoice and, hence, outcomes of the chance device are evaluated according to expected utility (EU). Without this assumption anticipated regret-rejoice could never explain repeated choice of option $I$ as active choices and delegated choices would have the same regret-rejoice consequences.

In contrast to option $I$, active choices of a risky, ambiguous, or certain prospect may lead to regret or rejoice and are therefore evaluated using a regret-rejoice utility (RRU) as introduced by Loomes and Sugden (1982). Hence, outcomes are evaluated according to $V(x, y)=u(x)+R(u(x)-u(y))$ where $x$ is the actual outcome, $y$ the counter-factual outcome, $u($.$) a "choiceless utility function" (Loomes and Sugden, 1982,$ p.807), and $R(x-y)$ the real-valued regret-rejoice function with $R(0)=0 ; R($.$) is non-decreasing. In the$ following, under slight abuse of notation we will simply write $x(y)$ for the assigned real-valued utility index $u(x)(u(y))$ for outcomes $x(y)$.

Regret-rejoice in experiment Risk-Ambi. Consider the 21 decisions between the risky and the ambiguous prospects in Risk-Ambi. Below the possible states of the world are listed, where $w_{R}\left(l_{R}\right)$ denotes that a winning (losing) ball is extracted from the risky urn and $w_{A}\left(l_{A}\right)$ denotes that a winning (losing) ball is extracted from the ambiguous urn. $L_{R}\left(L_{A}\right)$ denotes that the risky lottery matters for the payment when option $I$ was chosen.

The possible states of the world are:

$\begin{array}{cccccccc}\stackrel{S_{1}}{w_{R}}, \stackrel{S}{L}_{R}, w_{A} & w_{R}, \stackrel{S}{L}_{A}, w_{A} & l_{R}, \stackrel{S_{3}}{L_{R}, w_{A}} & l_{R}, \stackrel{S_{4}}{L_{A}, w_{A}} & l_{R}, \stackrel{S}{5}_{R}, l_{A} & l_{R}, \stackrel{S}{6}_{A}, l_{A} & \stackrel{S}{7}_{R}, l_{R}, l_{A} & \stackrel{S}{*}_{R}, S_{A}, l_{A}\end{array}$

Let $p\left(S_{r}\right)$ denote the probability that state $r$ is the true state of the world, $p_{r}$ the winning probability of the risky urn in decision situation $\mathrm{r}, q$ the subjective winning probability a participant assigns to the ambiguous urn, $x_{1}$ the choiceless utility index of winning the (high) prize (€15,- in the experiment), and $x_{2}$ the choiceless utility index of winning the (low) prize (€0,- in the experiment). Below we will assume $x_{2}=0$ w.l.o.g. 
It follows that the RRU of the risky prospect is not smaller than the EU of choosing option $I$, i.e., $R R U($ risky $) \geq E U($ option $I)$, if and only if:

$$
\begin{array}{r}
p\left(S_{1}\right)\left[x_{1}+f\left(x_{1}-x_{1}\right)\right]+p\left(S_{2}\right)\left[x_{1}+f\left(x_{1}-x_{1}\right)\right]+p\left(S_{3}\right)\left[x_{2}+f\left(x_{2}-x_{2}\right)\right]+p\left(S_{4}\right)\left[x_{2}+f\left(x_{2}-x_{1}\right)\right]+ \\
p\left(S_{5}\right)\left[x_{2}+f\left(x_{2}-x_{2}\right)\right]+p\left(S_{6}\right)\left[x_{2}+f\left(x_{2}-x_{2}\right)\right]+p\left(S_{7}\right)\left[x_{1}+f\left(x_{1}-x_{1}\right)\right]+p\left(S_{8}\right)\left[x_{1}+f\left(x_{1}-x_{2}\right)\right] \geq \\
p\left(S_{1}\right) x_{1}+p\left(S_{2}\right) x_{1}+p\left(S_{3}\right) x_{2}+p\left(S_{4}\right) x_{1}+p\left(S_{5}\right) x_{2}+p\left(S_{6}\right) x_{2}+p\left(S_{7}\right) x_{1}+p\left(S_{8}\right) x_{2} \\
\Leftrightarrow \\
p\left(S_{4}\right)\left[0-x_{1}+f\left(0-x_{1}\right)\right]+p\left(S_{8}\right)\left[x_{1}-0+f\left(x_{1}-0\right)\right] \geq 0 \\
\Leftrightarrow \\
\left(1-p_{r}\right) \frac{1}{2} q\left[-x_{1}+f\left(-x_{1}\right)\right]+p_{r} \frac{1}{2}(1-q)\left[x_{1}+f\left(x_{1}\right)\right] \geq 0 \\
\Leftrightarrow \\
p_{r}\left[x_{1}+f\left(x_{1}\right)-q f\left(-x_{1}\right)-q f\left(x_{1}\right)\right] \geq q\left[x_{1}-f\left(-x_{1}\right)\right] \\
\Leftrightarrow \\
p_{r}\left[x_{1}+[1-q] f\left(x_{1}\right)-q f\left(-x_{1}\right)\right] \geq q\left[x_{1}-f\left(-x_{1}\right)\right] \\
\Leftrightarrow \\
\Leftrightarrow
\end{array}
$$

Similarly, the RRU of the ambiguous prospect is not smaller than the EU of choosing option $I$, i.e., $R R U($ ambiguous $) \geq E U($ option $I)$, if and only if:

$$
\begin{aligned}
& p\left(S_{1}\right)\left[x_{1}+f\left(x_{1}-x_{1}\right)\right]+p\left(S_{2}\right)\left[x_{1}+f\left(x_{1}-x_{1}\right)\right]+p\left(S_{3}\right)\left[x_{1}+f\left(x_{1}-x_{2}\right)\right]+p\left(S_{4}\right)\left[x_{1}+f\left(x_{1}-x_{1}\right)\right]+ \\
& p\left(S_{5}\right)\left[x_{2}+f\left(x_{2}-x_{2}\right)\right]+p\left(S_{6}\right)\left[x_{2}+f\left(x_{2}-x_{2}\right)\right]+p\left(S_{7}\right)\left[x_{2}+f\left(x_{2}-x_{1}\right)\right]+p\left(S_{8}\right)\left[x_{2}+f\left(x_{2}-x_{2}\right)\right] \geq \\
& p\left(S_{1}\right) x_{1}+p\left(S_{2}\right) x_{1}+p\left(S_{3}\right) x_{2}+p\left(S_{4}\right) x_{1}+p\left(S_{5}\right) x_{2}+p\left(S_{6}\right) x_{2}+p\left(S_{7}\right) x_{1}+p\left(S_{8}\right) x_{2} \\
& p\left(S_{3}\right)\left[x_{1}-0+f\left(x_{1}-0\right)\right]+p\left(S_{7}\right)\left[0-x_{1}+f\left(0-x_{1}\right)\right] \geq 0 \\
& \left(1-p_{r}\right) \frac{1}{2} q\left[x_{1}+f\left(x_{1}\right)\right]+p_{r} \frac{1}{2}(1-q)\left[-x_{1}+f\left(-x_{1}\right)\right] \geq 0 \\
& q\left[x_{1}+f\left(x_{1}\right)\right] \geq p_{r}\left[x_{1}-[1-q] f\left(-x_{1}\right)+q f\left(x_{1}\right)\right] \\
& \Leftrightarrow \\
& p_{r} \leq \frac{q\left[x_{1}+f\left(x_{1}\right)\right]}{x_{1}-[1-q] f\left(-x_{1}\right)+q f\left(x_{1}\right)}:=\underline{p}_{\exp 1}
\end{aligned}
$$

To rationalize repeated choice of option $I$ as an optimal decision under regret-rejoice it must hold that $R R U$ (risky) $<E U$ (option $I$ ) and $R R U$ (ambiguous) $<E U$ (option $I$ ) and, hence, that there are some 
winning probabilities $p_{r}$ of the risky prospect such that $p_{r}<\bar{p}_{\exp 1}$ and $p_{r}>\underline{p}_{\exp 1}$ simultaneously hold. A first observation is that this can never hold when regret and rejoice have a symmetric effect as for $f\left(x_{1}\right)=-f\left(-x_{1}\right)$ equations (2) and (3) collapse to $\bar{p}_{\exp 1}=\underline{p}_{\exp 1}$. Further, a necessary condition for option $I$ to be an optimal choice is that

$$
\begin{aligned}
& \underline{p}_{\exp 1}<\bar{p}_{\exp 1} \Leftrightarrow \frac{q\left[x_{1}+f\left(x_{1}\right)\right]}{x_{1}-[1-q] f\left(-x_{1}\right)+q f\left(x_{1}\right)}<\frac{q\left[x_{1}-f\left(-x_{1}\right)\right]}{x_{1}+[1-q] f\left(x_{1}\right)-q f\left(-x_{1}\right)} \Leftrightarrow \\
& {\left[x_{1}+f\left(x_{1}\right)\right]\left[x_{1}+[1-q] f\left(x_{1}\right)-q f\left(-x_{1}\right)\right]<\left[x_{1}-f\left(-x_{1}\right)\right]\left[x_{1}-[1-q] f\left(-x_{1}\right)+q f\left(x_{1}\right)\right] \Leftrightarrow}
\end{aligned}
$$

(after some rearrangements)

$q\left[2 x_{1}\left[-f\left(-x_{1}\right)-f\left(x_{1}\right)\right]+\left[-f\left(-x_{1}\right)\right]^{2}-\left[f\left(x_{1}\right)\right]^{2}\right]<2 x_{1}\left[-f\left(-x_{1}\right)-f\left(x_{1}\right)\right]+\left[-f\left(-x_{1}\right)\right]^{2}-\left[f\left(x_{1}\right)\right]^{2}$.

In the last inequality both sides are identical, except for the multiplication with $q$ on the l.h.s. Hence, on the one hand, the inequality will be satisfied for all $q \in[0,1$ [ if the r.h.s. is strictly positive, that is, if $-f\left(-x_{1}\right)>f\left(x_{1}\right)$. On the other hand, it will never be satisfied for any $q \in\left[0,1\left[\right.\right.$ if $-f\left(-x_{1}\right) \leq f\left(x_{1}\right)$. Thus, the necessary condition for anticipated regret-rejoice to be an explanation for repeated choice of option $I$ in Risk-Ambi can be satisfied only if the disutility from anticipated regret is sufficiently stronger than the anticipated utility from rejoice.

Regret-rejoice in experiment Risk-Sure. Here we show that if regret-rejoice would be the motivational force behind the repeated choice of option $I$ in Risk-Ambi, we should observe repeated choice of option I also in Risk-Sure.

Recall that in Risk-Sure subjects made 21 decisions between varying risky lotteries and a fixed sure payment. Below the possible states of the world are listed, where $w_{R}\left(l_{R}\right)$ denotes that a winning (losing) ball is extracted from the risky urn. The letter $R$ indicates that the risky prospect is relevant, whereas the letter $S$ indicates that the sure payment is relevant, in case a subject has chosen option $I$ (i.e., has delegated the choice to the fair chance device). As before $x_{1}\left(x_{2}\right)$ denotes the choiceless utility index for the high and low prize, respectively. In the experiment the high prize was $€ 15$, the low prize $€ 0$, and the sure payment $€ 7,50$. We assume below $x_{2}=0$ and indicate the utility index of the sure payment by $x_{s}:=\alpha x_{1}(0<\alpha<1)$ w.l.o.g.

The possible states of the world are:

$\begin{array}{cccc}S_{1} & S_{2} & S_{3} & S_{4} \\ w_{R}, R & w_{R}, S & l_{R}, R & l_{R}, S .\end{array}$

It follows that the RRU of choosing a given risky prospect with winning probability $p_{r}$ is not smaller than the $\mathrm{EU}$ of choosing option $I$, i.e. $R R U$ (risky) $\geq E U$ (option $I$ ), if and only if:

$$
\begin{array}{r}
p\left(S_{1}\right)\left[x_{1}+f\left(x_{1}-x_{1}\right)\right]+p\left(S_{2}\right)\left[x_{1}+f\left(x_{1}-\alpha x_{1}\right)\right]+p\left(S_{3}\right)\left[x_{2}+f\left(x_{2}-x_{2}\right)\right]+p\left(S_{4}\right)\left[x_{2}+f\left(x_{2}-\alpha x_{1}\right)\right] \\
p\left(S_{1}\right) x_{1}+p\left(S_{2}\right) \alpha x_{1}+p\left(S_{3}\right) x_{2}+p\left(S_{4}\right) \alpha x_{1} \\
\Leftrightarrow \\
p_{r} \frac{1}{2}\left[x_{1}-\alpha x_{1}+f\left(x_{1}-\alpha x_{1}\right)\right]+\left(1-p_{r}\right) \frac{1}{2}\left[-\alpha x_{1}+f\left(-\alpha x_{1}\right)\right] \geq 0 \\
\Leftrightarrow \\
p_{r}\left[x_{1}+f\left(x_{1}-\alpha x_{1}\right)-f\left(-\alpha x_{1}\right)\right] \geq \alpha x_{1}-f\left(-\alpha x_{1}\right)
\end{array}
$$




$$
p_{r} \geq \frac{\alpha x_{1}-f\left(-\alpha x_{1}\right)}{x_{1}+f\left(x_{1}-\alpha x_{1}\right)-f\left(-\alpha x_{1}\right)}=: \bar{p}_{\exp 2} .
$$

Similarly, the RRU of the safe payment is not smaller than the expected utility of option $I$, i.e., $R R U($ safe $) \geq E U($ option $I)$, if:

$$
\begin{aligned}
& p\left(S_{1}\right)\left[\alpha x_{1}+f\left(\alpha x_{1}-x_{1}\right)\right]+p\left(S_{2}\right)\left[\alpha x_{1}+f\left(\alpha x_{1}-\alpha x_{1}\right)\right]+ \\
& p\left(S_{3}\right)\left[\alpha x_{1}+f\left(\alpha x_{1}-x_{2}\right)\right]+p\left(S_{4}\right)\left[\alpha x_{1}+f\left(\alpha x_{1}-\alpha x_{1}\right)\right] \geq p\left(S_{1}\right) x_{1}+p\left(S_{2}\right) \alpha x_{1}+p\left(S_{3}\right) x_{2}+p\left(S_{4}\right) \alpha x_{1} \\
& p_{r} \frac{1}{2}\left[\alpha x_{1}-x_{1}+f\left(\alpha x_{1}-x_{1}\right)\right]+\left[1-p_{r}\right] \frac{1}{2}\left[\alpha x_{1}+f\left(\alpha x_{1}\right)\right] \geq 0 \\
& p_{r}\left[-x_{1}+f\left(\alpha x_{1}-x_{1}\right)-f\left(\alpha x_{1}\right)\right] \geq-\left[\alpha x_{1}+f\left(\alpha x_{1}\right)\right] \\
& p_{r}\left[x_{1}-f\left(\alpha x_{1}-x_{1}\right)+f\left(\alpha x_{1}\right)\right] \leq \alpha x_{1}+f\left(\alpha x_{1}\right) \\
& \Leftrightarrow \\
& p_{r} \leq \frac{\alpha x_{1}+f\left(\alpha x_{1}\right)}{x_{1}-f\left(\alpha x_{1}-x_{1}\right)+f\left(\alpha x_{1}\right)}=: \underline{p}_{\exp 2} .
\end{aligned}
$$

To rationalize repeated choice of option $I$ as an optimal decision under regret-rejoice it must hold that $R R U($ risky $)<E U($ option $I)$ and $R R U($ safe $)<E U($ option $I)$ and, hence, that there are some winning probabilities $p_{r}$ of the risky prospect such that $p_{r}<\bar{p}_{\operatorname{exp2}}$ and $p_{r}>\underline{p}_{\exp 2}$ simultaneously hold. From conditions (4) and (5) it follows that $\underline{p}_{\exp 2}<\bar{p}_{\text {exp } 2}$ is a necessary condition for this to hold; or equivalently

$$
\frac{\alpha x_{1}+f\left(\alpha x_{1}\right)}{x_{1}-f\left(\alpha x_{1}-x_{1}\right)+f\left(\alpha x_{1}\right)}<\frac{\alpha x_{1}-f\left(-\alpha x_{1}\right)}{x_{1}+f\left(x_{1}-\alpha x_{1}\right)-f\left(-\alpha x_{1}\right)} .
$$

After some rearrangements this inequality can be written as

$$
\begin{array}{r}
\alpha x_{1}\left[f\left(x_{1}[1-\alpha]\right)+f\left(-x_{1}[1-\alpha]\right)\right]+[1-\alpha] x_{1}\left[f\left(\alpha x_{1}\right)+f\left(-\alpha x_{1}\right)\right]+ \\
f\left(x_{1}[1-\alpha]\right) f\left(\alpha x_{1}\right)-f\left(-x_{1}[1-\alpha]\right) f\left(-\alpha x_{1}\right)<0,
\end{array}
$$

which can hold only if $f(z)<-f(-z)$, i.e., when regret generates a stronger disutility than rejoice generates additional utility.

To see this suppose to the contrary that $f(z) \geq-f(-z)$. It is easy to see that for $f(z)=-f(-z)$ all terms vanish and the inequality can thus not be satisfied. Therefore, suppose $f(z)>-f(-z)$. It follows that both terms in square brackets (first row of the inequality) are strictly positive. It is now sufficient to show that $f\left(x_{1}[1-\alpha]\right) f\left(\alpha x_{1}\right)-f\left(-x_{1}[1-\alpha]\right) f\left(-\alpha x_{1}\right)>0$. Note, that $f\left(x_{1}[1-\alpha]\right)>-f\left(-x_{1}[1-\alpha]\right)>0$ and $f\left(\alpha x_{1}\right)>-f\left(-\alpha x_{1}\right)>0$ and, hence, $f\left(x_{1}[1-\alpha]\right) f\left(\alpha x_{1}\right)>-f\left(-x_{1}[1-\alpha]\right) f\left(\alpha x_{1}\right)>0$ as well as $-f\left(-x_{1}[1-\alpha]\right) f\left(\alpha x_{1}\right)>-f\left(-x_{1}[1-\alpha]\right)\left[-f\left(-\alpha x_{1}\right)\right]>0$, which implies $f\left(x_{1}[1-\alpha]\right) f\left(\alpha x_{1}\right)>-f\left(-x_{1}[1-\right.$ $\alpha])\left[-f\left(-\alpha x_{1}\right)\right]$ and, thus, $f\left(x_{1}[1-\alpha]\right) f\left(\alpha x_{1}\right)-f\left(-x_{1}[1-\alpha]\right) f\left(-\alpha x_{1}\right)>0$.

That regret is sufficiently stronger than rejoice is also a necessary condition for the regret-rejoice motive to rationalize repeated choice of option $I$ in Risk-Ambi. Therefore, if regret-rejoice would explain repeated choice of option $I$ there, we should observe repeated choice of option $I$ also in Risk-Sure. However, as shown in Section 4 this is not the case. 


\section{Instructions of the Experiment}

We report here the original instructions used in experiment Risk-Ambi and in brackets the parts changing in experiment Risk-Sure. The instructions used in Risk-Ambi-high are identical except for the increased winning prize of the ambiguous prospect and available upon request. The instructions were computerized.

\section{C.1 Part 1}

Shortly you are going to face 21 choice situations (situations 1-21). These choice situations will involve two urns (i.e. boxes). These urns really exist and they will play an important role in determining your earnings. You might have seen them on the table when you entered the lab. At the end of the experiment you will have the possibility to personally check their content.

In one urn there are 100 balls colored black and red. The exact number of black and red balls contained in this urn is always displayed in the decision table that you will see shortly. For convenience we call this urn Urn A. The other urn, that we call Urn B, contains 100 balls as well. However, the exact number of black and red balls in this urn is unknown to you. In fact, the composition of Urn B is also unknown to us because it was composed by a colleague of us and sealed thereafter, while we were absent. Our colleague was free to put any number of red and/or black balls into this urn provided the total number of balls is 100 .

In each choice situation you will be asked to bet on a draw of a ball of a certain color by selecting one of the two different types of urns. You are first given the possibility to select the color (black or red) that you like to bet on. The color you select will neither be to your advantage nor to your disadvantage. Also note that you will choose the color once for all choice situations.

[Shortly you are going to face 21 choice situations (situations 1-21). These choice situations will involve one urn (i.e. a box). This urn really exists and it will play an important role in determining your earnings. In the urn there are 100 balls colored black and red. The exact number of black and red balls contained in the urn changes in each choice situation and is always displayed in the decision table that you will see shortly. In each choice situation you will be asked whether you want to bet on a draw of a ball of a certain color from the urn or whether you prefer to receive a certain amount of money. You are first given the possibility to select the color (black or red) that you like to bet on. The color you select will neither be to your advantage nor to your disadvantage. Also note that you will choose the color once for all choice situations.]

This is a screen shot of a part of the table you are going to see. Each row of the table represents one choice situation:

In each row you have to decide between Urn A and Urn B to bet on the color you have selected. You can also state that you are indifferent between the two urns.

Recall that Urn B contains an unknown proportion of 100 black and red balls. Urn A contains 100 balls as well: the proportion of black and red balls is always displayed in the table.

[In each row you have to decide whether you want to bet on the color you have selected or whether you want to receive 7.50 Euro for sure. You can also state that you are indifferent between these two options. ] 


\begin{tabular}{|c|c|c|c|}
\hline \multicolumn{4}{|c|}{ Remember that the color you have chosen to bet on is Red } \\
\hline CHOICE SITUATION & COMPOSITION OF URIN A & & COMPOSTION OF URN E \\
\hline 1. I bet on: & $\Gamma 100$ red balls & $\Gamma$ lam indifferert bewwen the wo urns & I 100 black and red balls in unkrown color ratio \\
\hline 2. I bot on: & 95 red balls +5 black balls & $\Gamma$ lam indifferert betwe en the two urns & I 100 black and red balls in unknown color ratio \\
\hline 3. I bet on: & $\Gamma 90$ red balls +10 black balls & $\Gamma$ lam indifferent belween the wo urns & I00 black and red bals in unknown color ratio \\
\hline 4. Iot on: & $\lceil 85$ red balls +15 black balls & $\Gamma$ a am inoirferent bewwen the wo urns & I 100 black and red bals in unkrown color ratio \\
\hline 5. I bet on: & $\Gamma 80$ red balls +20 black balls & $\Gamma$ lam inoifterert beween the wo urns & I 100 black and red balls in unknown color ratio \\
\hline 6. Ibat on: & F 75 red balls +25 black balls & $\Gamma$ lam indifferent between the wo urns & I 100 black and red balls in unknown color r ratio \\
\hline 7.1 bet on: & $\Gamma 70$ rod balls +30 black balls & $\Gamma$ lam indifferent betwoen the two urns & IC 100 black and rod balls in unknown color ratio \\
\hline 8. Ibet on: & $\Gamma 65$ red balls +35 black balls & $\Gamma$ am indifferent between the two urns & IC 100 black and red balls in unkrown color ratio \\
\hline 9. I bet on: & $\lceil$ 60 red balls +40 black balls & $\Gamma$ l am inoliterert peween the wo urns & I 100 black and red balls In unknown color ratio \\
\hline 10. I bet on: & $\Gamma 55$ red balls +45 black balls & $\Gamma$ lam indifferent between the wo urns & 100 black and red balls in unkrown color ratio \\
\hline 11.1 bet on: & $\Gamma 50$ red balls +50 black balls & $\Gamma$ l am indifferert between the wo urns & I 100 black and red balls in unknown color ratio \\
\hline 12. I bet on: & $\Gamma 45$ red balls +55 black balls & $\Gamma$ am indifferent between the wo urns & 100 black and red balls in unknown color ratio \\
\hline
\end{tabular}

\section{Determination of earnings}

At the end of the experiment one of the choice situations in the table is randomly selected with equal probability to determine your earnings. Thereafter, a ball is drawn from the urn you decided to bet on in the choice situation that was randomly selected.

Suppose, for example, that red is your color and that choice situation 7 is randomly selected. Suppose further that you decided to bet on Urn A in that choice situation. At the end of the experiment, a ball is drawn from Urn A, which contains 70 red balls and 30 black balls in choice situation 7 . You receive 15 Euro if the ball is red and nothing otherwise.

Similarly, if in choice situation 7 you have decided to bet on Urn B, which contains 100 balls in unknown color composition, a ball is drawn from it. You receive 15 Euro if the ball is red and nothing otherwise. In case you were indifferent between the two urns, one is randomly selected with equal probability to determine your earnings.

[ At the end of the experiment one of the choice situations in the table is randomly selected with equal probability to determine your earnings. Depending on which choice situation is selected, the experimenter will put the appropriate number of red and black balls in the urn. For instance, if choice situation 12 is selected for payment, the experimenter will put 55 red balls and 45 black balls in the urn. At the end of the experiment you will have the possibility to personally check the content of the urn.

Suppose, for example, that you selected red and that choice situation 7 is randomly selected at the end of the experiment. Suppose further that you chose to bet on the urn in that choice situation. A ball is then drawn from the urn which contains 70 red balls and 30 black balls in situation 7 . You receive 15 Euro if the ball is red and nothing otherwise.

Differently, the ball drawn from the urn does not influence your earnings if in choice situation 7 you decided that you prefer to get 7.50 Euro for sure. In case you were indifferent between betting on the urn and earning 7.50 Euro for sure, one of these two options is randomly selected with equal probability to determine your earnings. ]

\section{Estimation of the composition of Urn B}

Now that you have made your choices, we would like to ask you for your best estimate of the color composition of Urn B. 
The categories below are intervals indicating the number of red balls that might be contained in Urn B. Please click on the check box that represents your best estimate. You can also click on more than one box.

Consider the following random examples.

For instance, if you believe that there are between 12 and 34 red balls in Urn B, you should click on the 3rd, 4th, 5th 6 th and 7 th check box from the left.

For instance, if you believe that there are between 72 and 74 red balls in Urn B than you should click on the 15 th check box form the left.

For instance, if you believe that there are exactly 6 red balls in Urn B than you should click on the 2nd check box from the left.

If you believe that there between 17 and 24 red balls or between 63 and 69 red balls in Urn B then you should click on the 4th, 5th, 13th and 14th check box. Notice that this part was not included in experiment Risk-Sure.

\section{C.2 Part 2}

You are now going to make another series of choices. These choices will not influence your earnings from the choices you just made, nor will your earlier choices influence the earnings from the choices you are going to make. After you have made the these choices you will be asked to answer some questions. Thereafter the experiment will be over.

In the following, you will be confronted with a series of 33 decision situations that will appear in random order on the screen. All these decision situations are completely independent of each other. A choice you made in one decision situation does not affect any of the other following decision situations.

Each decision situation is displayed on a screen. The screen consists of 20 rows. You have to decide for every row whether you prefer option A or option B. Option A is a lottery and is the same for every row in a given decision situation, while the secure option B takes 20 different values, one for each row. By clicking on NEXT you will see an example screen of a decision situation.

This is a screen shot of one decision situation you are going to face. You are not asked to make choices now! Please have a careful look. Determination of earnings

At the end of the experiment one of the 33 decision situations will be randomly selected with equal probability. Once the decision situation is selected, one of the 20 rows in this decision situation will be randomly selected with equal probability.

The choice you have made in this specific row will determine your earnings. Consider, for instance, the screen shot that you have just seen.

Option A gives you a $55 \%$ chance to earn 10.- Euro and a $45 \%$ chance to earn nothing. Option B is always a sure amount that ranges from 10.- Euro in the first row, to 0.50 Euro in the 20th row. Suppose that the 12 th row is randomly selected. If you would have selected option B, you would receive 4.50 Euro. If, instead, you would have selected option A, the outcome of the lottery determines your earnings. The lottery will be paid out by publicly drawing a card from a stack of numbered cards.

Please note that each decision situation has the same likelihood to be the one that is relevant for your 


\begin{tabular}{|c|c|c|c|}
\hline 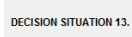 & $\begin{array}{l}\text { OPTIONA } \\
\text { LOTIERY }\end{array}$ & rour choice & $\begin{array}{l}\text { OPTION B } \\
\text { SUREAMOUNT }\end{array}$ \\
\hline choice 1 & & $A \subset C B$ & 10. \\
\hline choice 2 & & $A \subset C B$ & 9.50 \\
\hline choice 3 & & $A \subset \subset B$ & 9.- \\
\hline choice 4 & & $A \subset C B$ & 8.50 \\
\hline choice 5 & & $A C C B$ & 8.- \\
\hline choice 6 & & $A C C B$ & 7.50 \\
\hline choice 7 & With $55 \%$ chance you receive 10 . Euro, & $A \subset C B$ & 7. \\
\hline choice 8 & & $A \subset C B$ & 6.50 \\
\hline choice 9 & & $A C C B$ & 6. \\
\hline choice 10 & & $A \subset C B$ & 5.50 \\
\hline choice 11 & & $A C C B$ & 5.- \\
\hline choice 12 & & $A C C B$ & 4.50 \\
\hline choice 13 & & $A \subset C B$ & 4.- \\
\hline choice 14 & & $A C C B$ & 3.50 \\
\hline choice 15 & & $A r C B$ & 3.- \\
\hline choice 16 & & $A \subset C B$ & 2.50 \\
\hline choice 17 & & $A C C B$ & 2.- \\
\hline choice 18 & & $A C C B$ & 1.50 \\
\hline choice 19 & & $A C C B$ & 1.- \\
\hline choice 20 & & $A C C B$ & 0.50 \\
\hline
\end{tabular}

earnings. Therefore, you should view each decision independently and consider all your choices carefully.

\section{C.3 Part 3}

\section{Cognitive Reflection Test}

You have now finished with the 33 decision situations. In the following screens we ask you to answer some questions. Please read the following questions carefully and type your answer in the boxes. You will earn 0.50 Euro for each correct answer provided.

(1) A bat and a ball cost 1.10 Euro in total. The bat costs 1.00 Euro more than the ball. How many cents does the ball cost?

(2) If it takes 5 machines 5 minutes to make 5 widgets, how long (in minutes) would it take 100 machines to make 100 widgets?

(3) In a lake, there is a patch of lily pads. Every day, the patch doubles in size. If it takes 48 days for the patch to cover the entire lake, how many days would it take for the patch to cover half of the lake?

(4) Two cars are on a collision course, traveling towards each other in the same lane. Car A is traveling $70 \mathrm{~km}$ an hour. Car B is traveling $80 \mathrm{~km}$ an hour. How far apart are the cars one minute before they collide? Please answer in $\mathrm{km} 23$

\footnotetext{
${ }^{23}$ This question is not part of the original CRT by Shane (2005). We added it to increase the complexity of the task. However, in the data analysis we do not consider answers to this question.
} 


\section{Rational Experiential Inventory}

What is your opinion on the following statements?(subjects had to answer on a 5 point scale, where $1=$ "completely false"; $5=$ "completely true")

1. I would rather do something that requires little thought than something that is sure to challenge my thinking abilities

2. I don't like to have the responsibility of handling a situation that requires a lot of thinking.

3. I would prefer complex to simple problems.

4. I find little satisfaction in deliberating hard and for long hours.

5. Thinking is not my idea of fun.

6. The notion of thinking abstractly is not appealing to me.

7. I prefer my life to be filled with puzzles that I must solve.

8. Simply knowing the answer rather than understanding the reasons for the answer to a problem is fine with me.

9. I don't reason well under pressure.

10. The idea of relying on thought to make my way to the top does not appeal to me.

11. I prefer to talk about international problems rather than gossip about celebrities.

12. Learning new ways to think doesn't excite me very much.

13. I would prefer a task that is intellectual, difficult, and important to one that is somewhat important but does not require much thought.

14. I generally prefer to accept things as they are rather than to question them.

15. It is enough for me that something gets the job done, I don't care how or why it works.

16. I tend to set goals that can be accomplished only by expending considerable mental effort.

17. I have difficulty thinking in new and unfamiliar situations.

18. I feel relief rather than satisfaction after completing a task that required a lot of mental effort.

19. I try to anticipate and avoid situations where there is a likely chance I will have to think in depth about something.

20. My initial impressions of people are almost always right.

21. I trust my initial feelings about people.

22. When it comes to trusting people, I can usually rely on my "gut feelings."

23. I believe in trusting my hunches.

24. I can usually feel when a person is right or wrong even if I can't explain how I know.

25. I am a very intuitive person.

26. I can typically sense right away when a person is lying.

27. I am quick to form impressions about people.

28. I believe I can judge character pretty well from a person's appearance.

29. I often have clear visual images of things.

30. I have a very good sense of rhythm.

31. I am good at visualizing things. 


\section{Screen Shot of Decision Situations}

Figure D.1 displays a screen shot of the whole decision table in Risk-Ambi.

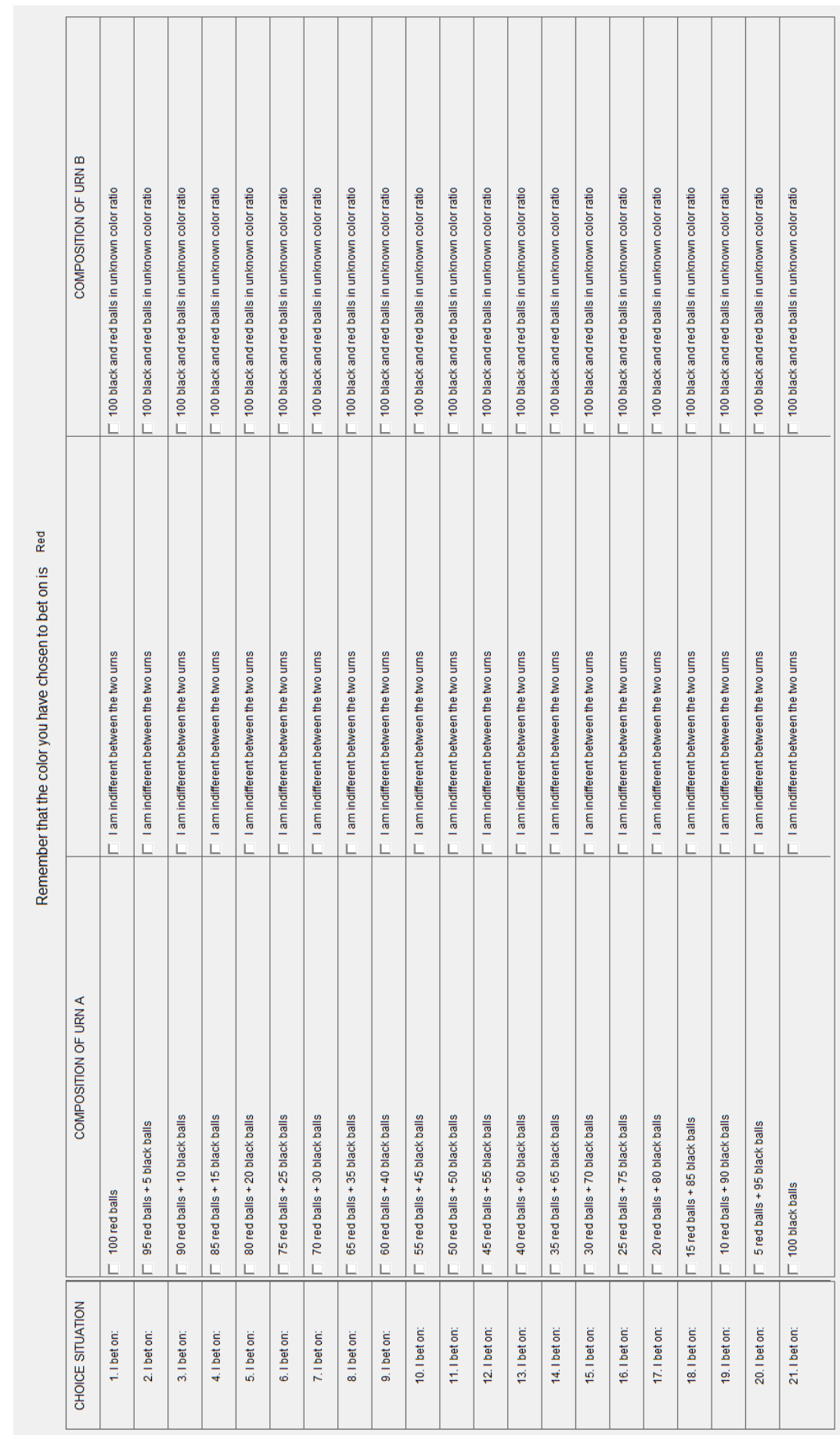

Figure D.1: Decision table in Part 1. 


\section{E Robustness Checks}

In the following we present results for the three experiments when the analysis is conducted with all participants, including those who have taken (weakly) dominated choices.

\section{E.1 Experiment Risk-Ambi}

The number of choices in favor of the risky prospect is significantly larger than 50 percent in all decision situations characterized by $p \geq 0.5$ ( $p$-value $<0.01)$. Choices favoring the ambiguous prospect are significantly larger than 50 percent in all choice situations characterized by $p \leq 0.4(p$-value $<0.01)$. In the decision situation where $p=0.45$, the number of individuals choosing the risky prospect is not significantly different than the number choosing the ambiguous one $(p$-value $=0.11)$.

Option $I$ is chosen by 35 percent of the subjects when $p=0.50$, by 38 percent when $p=0.45$, and by 35 percent when $p=0.40$ and $p=0.35$. In all the other decision situations, option $I$ is chosen by at most 22 percent of the subjects. The histogram in Figure E.1 reports the relative frequency of subjects that choose option $I$ for $n$ times. Only 22 percent of the subjects never select option $I$ and 20 percent select it exactly once. The remaining 58 percent of the subjects choose option $I$ in at least two decision situations.

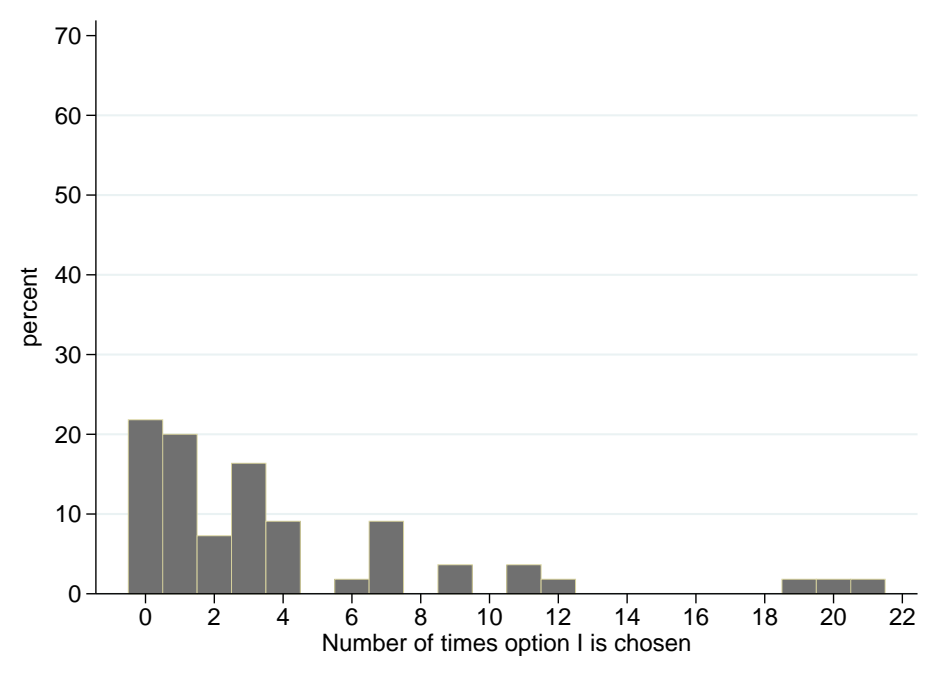

Figure E.1: Risk-Ambi - Relative frequency of participants choosing option $I n$ times.

Likelihood insensitivity We find that on average subjects who choose option $I$ more than once are characterized by $\alpha=0.92$ and $\gamma=0.39$. A Wilcoxon signed-rank test shows that $\gamma$ is significantly higher than the threshold value of $0.2(p$-value $<0.01)$. When considering all participants to the experiment we find that $\alpha=0.89$ and $\gamma=0.43$ on average.

Hence, overall the results of Risk-Ambi reported in the main text also hold when using the whole sample. 


\section{E.2 Experiment Risk-Sure}

Figure E.2 reports the relative frequency of choices in favor of option $I$ when participants make choices between risky prospects and a safe payment of $€ 7,50$. A comparison with Figure 2 shows that there are no substantial differences and the results reported in the main text also hold here.

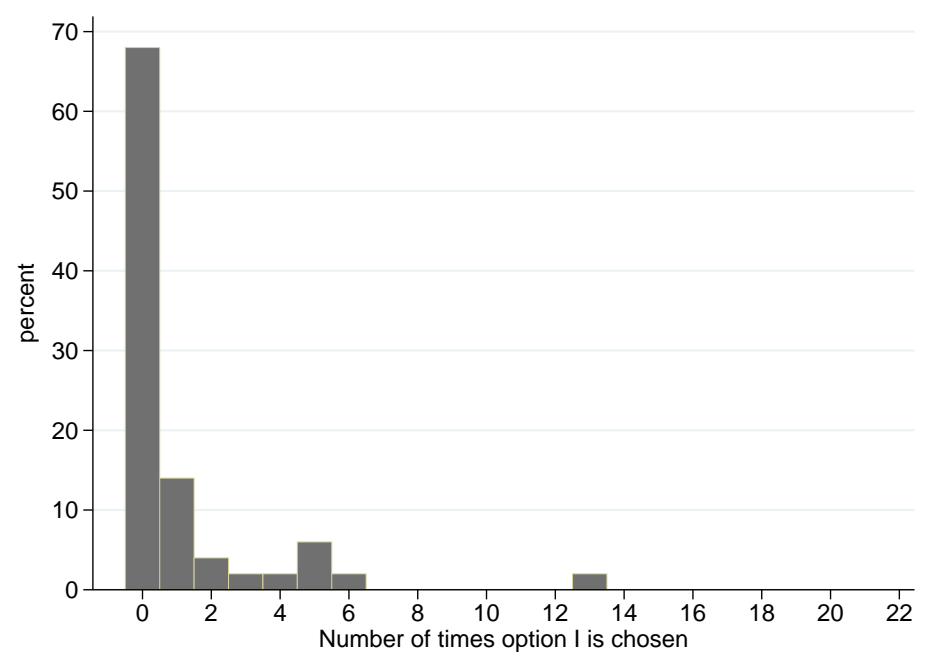

Figure E.2: Risk-Sure - Relative frequency of participants choosing option $I$.

\section{E.3 Experiment Risk-Ambi-high}

A binomial test shows that the risky prospect is chosen by more than 50 percent of the subjects in all choice situations characterized by a winning probability of at least 0.55 ( $p$-value $\leq 0.02)$. Choices in favor of the ambiguous prospect are significantly larger than 50 percent in all choice situations where the winning probability of the risky prospects is at most 0.45 ( $\mathrm{p}$ - value $\leq 0.03$ ). When the winning probability is 50 percent subjects do not clearly favor one type of prospect $(p$-value $=0.19)$. Figure E.3 shows a histogram of the relative frequency of indecisive choices. Similarly to the results reported in the main text, approximately one third of the subjects never choose option $I$, whereas almost 60 percent choose it in at least two decision situations.

Figure E.4 shows how choices in favor of option $I$ are distributed over the decision situations in RiskAmbi and Risk-Ambi-high. Behavior in Risk-Ambi-high is qualitatively consistent with the predictions based on the existence of incomplete preferences. That is, in comparison to Risk-Ambi, option $I$ is more frequent in decision situations characterized by a higher winning probability. We conduct Chi-square tests in every decision situation and test the hypothesis that option $I$ is chosen by the same number of subjects in the two experiments. Due to the behavior of inconsistent subjects, especially in Risk-Ambi, we observe that in a few decision situations option $I$ is significantly more frequently chosen in that experiment than in Risk-Ambi-high. Thus, overall, the results are similar to those reported in the main text, except that the comparative statics predictions fail to be confirmed. 


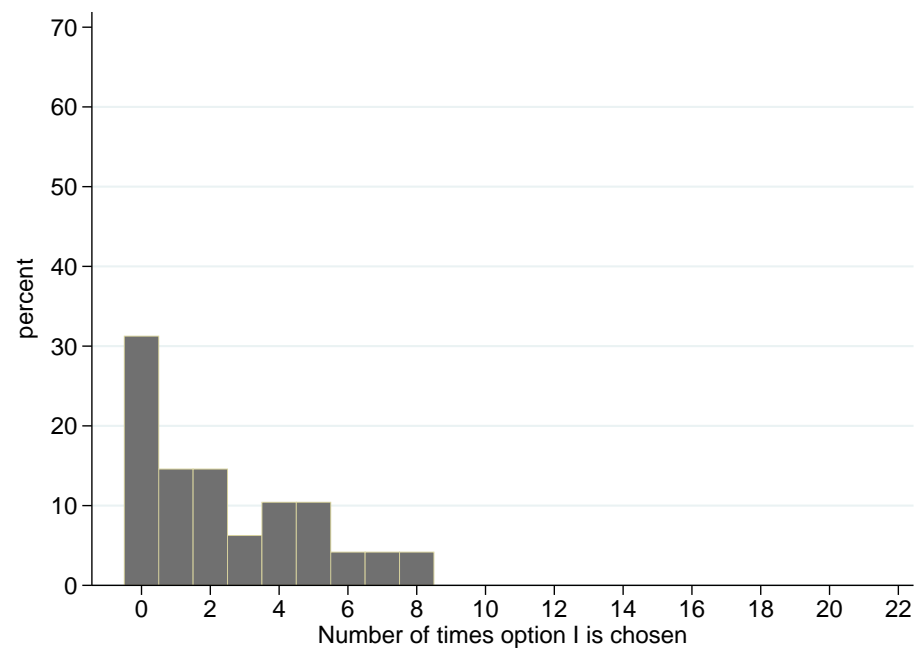

Figure E.3: Risk-Ambi-high-Relative frequency of participants choosing option $I$.

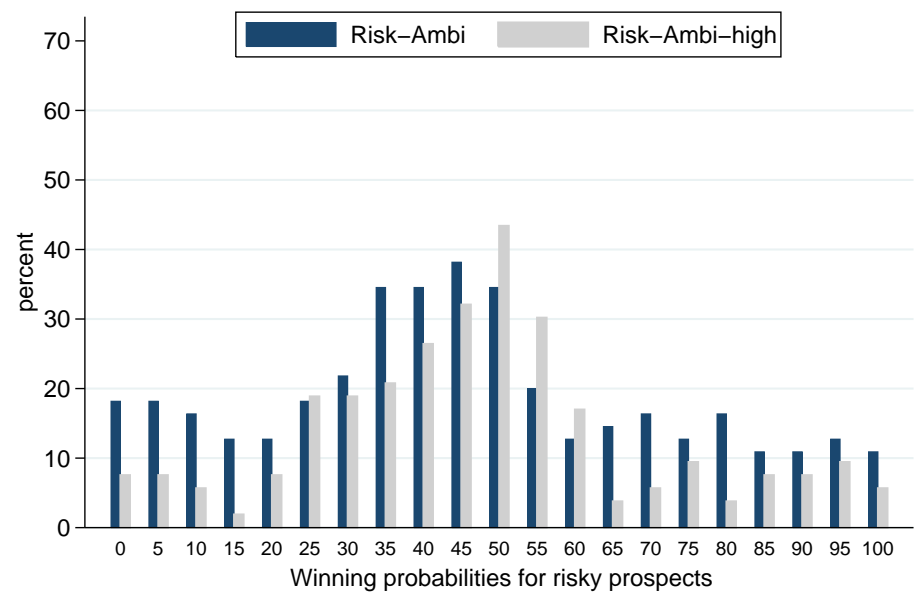

Figure E.4: Frequencies of choices of option I in Risk-Ambi and Risk-Ambi-high. 


\section{F Individual characteristics}

In the following we present some descriptive statistics on the participants' individual characteristics, as measured in the last part of the experiment, and relate them to choices in favor of option $I$. Since we do not observe significant differences between subjects participating in Risk-Ambi and Risk-Ambi-high, we pool the data of these two experiments. In order to investigate how cognitive abilities and thinking styles affect decision making in part 1 of the experiments, subjects are administered the Cognitive Reflection Test (CRT) (Frederick, 2005) and the Rational-Experiential Inventory (Epstein et al., 1996). The CRT is a 3 items test that measures the ability to reflect on a problem. The score ranges from 0 to 1 , where higher values indicate a higher performance. Subjects are rewarded with $€ 0.50$ for each correct answer and have a limited time. The REI includes a measure on a 5 point scale of analytical-rational processing (abbreviated as NFC, Need For Cognition) and another measure, also on a 5 points scale, of engagement and confidence in one's intuitive abilities (abbreviated as FI, Faith in Intuition). In the following we first report results for participants who did not make weakly dominated choices, followed by the results when taking all participants into account.

Table F.1 compares individual characteristics of participants who choose option $I$ at most once with those choosing option $I$ at least twice. The table also includes information on gender and means of the parameters estimates that capture the shape of subjects' probability weighting and value function. Individuals that choose Option $I$ more than once appear to be quite similar in the measured characteristics to those who only choose it at most once, except that there are more female subjects in the former group. Regression results in Table F.2 confirm that gender is the only significant correlate of repeated choice of option $I$.

Table F.1: Individual characteristics by number of times option $I$ is chosen.

\begin{tabular}{lll}
\hline \hline & Option $I \leq 1$ & Option $I>1$ \\
\hline male & $73 \%$ & $33 \%$ \\
mean CRT & $0.57(0.35)$ & $0.47(0.29)$ \\
mean NFC & $2.35(0.39)$ & $2.40(0.34)$ \\
mean FI & $3.39(0.58)$ & $3.60(0.54)$ \\
mean $\gamma$ & $0.48(0.23)$ & $0.39(0.22)$ \\
mean $\alpha$ & $0.82(0.26)$ & $0.87(0.23)$ \\
$\mathrm{N}$ & 33 & 40 \\
\hline
\end{tabular}

Note: Standard deviations in parentheses.

Tables F.3 and F.4 report the same analysis when taking all participants into account. Results are very similar, except that the gender difference vanishes. 
Table F.2: Determinants of number of option $I$ choices (OLS)

(no weakly dominated choices)

\begin{tabular}{llc}
\hline \hline & Coefficient & (Std. Err.) \\
\hline male & $-1.945^{* * *}$ & $(0.635)$ \\
CRT & -0.558 & $(0.795)$ \\
NFC & 0.787 & $(0.698)$ \\
FI & -0.120 & $(0.455)$ \\
$\gamma$ & -0.056 & $(1.403)$ \\
$\alpha$ & 0.761 & $(1.035)$ \\
Constant & 1.537 & $(2.534)$ \\
$N$ & \multicolumn{2}{c}{73} \\
$R^{2}$ & \multicolumn{2}{c}{0.198} \\
$F_{(6,66)}$ & \multicolumn{2}{c}{2.716} \\
\hline
\end{tabular}

Table F.3: Individual characteristics by number of times option $I$ is chosen.

\begin{tabular}{lll}
\hline \hline & Option $I \leq 1$ & Option $I>1$ \\
\hline male & $71 \%$ & $44 \%$ \\
mean CRT & $0.50(0.36)$ & $0.47(0.30)$ \\
mean NFC & $2.38(0.39)$ & $2.43(0.35)$ \\
mean FI & $3.39(0.56)$ & $3.57(0.51)$ \\
mean $\gamma$ & $0.44(0.23)$ & $0.37(0.24)$ \\
mean $\alpha$ & $0.81(0.24)$ & $0.90(0.32)$ \\
$\mathrm{N}$ & 45 & 63 \\
\hline
\end{tabular}

Note: Standard deviations in parentheses. 
Table F.4: Determinants of number of option $I$ choices (OLS)

(no weakly dominated choices)

\begin{tabular}{lcc}
\hline \hline & Coefficient & (Std. Err.) \\
\hline male & -0.737 & $(0.945)$ \\
CRT & 0.173 & $(1.286)$ \\
NFC & 0.886 & $(1.122)$ \\
FI & -0.358 & $(0.776)$ \\
$\gamma$ & -0.870 & $(1.964)$ \\
$\alpha$ & 1.404 & $(1.426)$ \\
Constant & 2.039 & $(4.173)$ \\
$N$ & \multicolumn{2}{c}{108} \\
$R^{2}$ & \multicolumn{2}{c}{0.026} \\
$F_{(6,101)}$ & \multicolumn{3}{c}{.455} \\
\hline
\end{tabular}

